\title{
Numerical Analysis and Parameter Optimization of Wear Characteristics of Titanium Alloy Cross Wedge Rolling Die
}

\author{
Zhanshuo Peng ${ }^{1}$, Hongchao Ji ${ }^{1, *}+\mathbb{C}$, Xiaomin Huang ${ }^{2}$, Baoyu Wang ${ }^{2, *} \mathbb{C}$, Wenchao Xiao ${ }^{3}$ and Shufu Wang ${ }^{1}$ \\ 1 College of Mechanical Engineering, North China University of Science and Technology, \\ Tangshan 063210, China; pzs@stu.ncst.edu.cn (Z.P.); 18731863262@163.com (S.W.) \\ 2 School of Mechanical Engineering, University of Science and Technology Beijing, Beijing 100083, China; \\ b20202050@xs.ustb.edu.cn \\ 3 School of Engineering and Technology, China University of Geosciences, Beijing 100083, China; \\ xiaowc@cugb.edu.cn \\ * Correspondence: jihongchao@ncst.edu.cn (H.J.); bywang@ustb.edu.cn (B.W.); Tel.: +86-0315-8805-440 (H.J.); \\ $+86-010-8237-5671$ (B.W.)
}

check for updates

Citation: Peng, Z.; Ji, H.; Huang, X.; Wang, B.; Xiao, W.; Wang, S.

Numerical Analysis and Parameter Optimization of Wear Characteristics of Titanium Alloy Cross Wedge Rolling Die. Metals 2021, 11, 1998. https://doi.org/10.3390/met11121998

Academic Editor: Diego Celentano

Received: 27 October 2021

Accepted: 7 December 2021

Published: 10 December 2021

Publisher's Note: MDPI stays neutral with regard to jurisdictional claims in published maps and institutional affiliations.

Copyright: (c) 2021 by the authors. Licensee MDPI, Basel, Switzerland. This article is an open access article distributed under the terms and conditions of the Creative Commons Attribution (CC BY) license (https:// creativecommons.org/licenses/by/ $4.0 /)$.

\begin{abstract}
Cross wedge rolling has the advantages of high production efficiency, good product quality, high material utilization, environmental protection, and low cost. It is one of the best processing methods for producing shaft blanks. In this paper, a cross wedge rolling die of TC4 titanium alloy is studied. Based on the Archard wear model, a modified model suitable for cross wedge rolling die wear analysis is derived through finite element simulation. Then, the modified Archard wear model is imported into Deform-3D software for finite element analysis. Orthogonal experimental design is used to combine and analyze different process parameters. Finally, the beetle antennae search (BAS)-genetic algorithm (GA)-back propagation neural network (BPNN) algorithm is used to predict the degree of die wear and to optimize the simulation parameters, which can acquire the process parameters that have the least impact on die wear. The results show that the wear distributions of cross wedge rolling tools is uneven. In general, the most serious areas are basically concentrated in the wedge-shaped inclined plane and rectangular edge lines. The reason is that the tangential force and radial force received by the die are relatively large, which leads to increased wear. Moreover, the temperature change is most severe on the wedge-shaped ridge line. When in contact with the workpiece, the temperature rises sharply, which makes the local temperature rise, the mold hardness decrease, and the wear accelerate. Through response surface method (RSM) analysis, it is concluded that the deformation temperature is the main factor affecting wear depth, followed by the forming angle, and that there is an interaction between the two factors. Finally, the feasibility of the BAS-GA-BP algorithm for optimizing the wear behavior of dies is verified, which provides a new process parameter optimization method for the problem of die wear in the cross wedge rolling process.
\end{abstract}

Keywords: cross wedge rolling; modified Archard wear model; orthogonal test; BAS-GA-BP algorithm; parameter optimization

\section{Introduction}

After decades of development, cross wedge rolling has become a more mature forming process for shaft parts. At present, cross wedge rolling is considered to be one of the best technological methods for producing shafts [1-3]. Compared with other traditional machining processes, cross wedge rolling has the advantages of high production efficiency, good product quality, environmental protection, and low cost [4]. In the process of cross wedge rolling, the failure mode of the die is more complicated. Most failure situations are caused by plastic deformation of the die, severe die wear, and die fracture. In actual production, failure of mechanical parts caused by wear accounts for $60-80 \%$ of all failure 
modes [5]. Therefore, the task of reducing die wear has become an important issue in cross wedge rolling production.

Abrasion is the process of continuous damage to the surface material of objects in contact with each other in relative motion; it is an inevitable result of friction. Die wear factors-prediction and calculation, adhesion wear and oxidation wear mechanisms, wearresistant coating, and so on-were analyzed. The analysis of the abovementioned factors affecting die wear plays an important role in reducing die loss and prolonging service life [6]. Iwadoh et al. [7] established an equation to calculate the maximum wear amount. Luo et al. [8-10] adopted the Archard model to calculate wear. Kang [11] and Behrens [12] optimized the traditional Archard wear model and defined die hardness as a function of temperature. In addition, Lee and Jou [13] further modified the traditional Archard wear model described above. Not only is the influence of die temperature on mold hardness considered but also the impact of die temperature on mold wear. So far, a large amount of research work on wear has used the modified Archard wear model proposed by Lee and Jou [14-16] to predict the wear behavior of molds.

With the continuous advancement of machine learning, data-mining algorithms, and computer technology, some scholars have tried to apply ANN [17], BP neural networks [18,19], GA-BP neural networks [20], BAS-BP neural networks, particle swarm optimization (PSO)-BP neural networks, and other machine-learning algorithms for flow stress prediction, wear prediction, and parameter optimization. Among them, the beetle antennae search (BAS) algorithm was proposed by Jiang and Li et al. [21,22], which is a bionic heuristic algorithm based on the biological behavior of long-bearded longhorns to detect and find food. Detection and search functions are realized by imitating the search function and random walking mechanism of the beetle in nature, which shows wide applicability and effectiveness in solving the multi-objective function-optimization problem. It is simple and flexible, avoids local optimal solutions, and is suitable for high-dimensional search.

At present, it is economically costly to study the relationship between mold-wear depth and cross wedge rolling process parameters through experimental methods. Therefore, in this paper, a cross wedge rolling model is established and an orthogonal experimental design is implemented. Finite element simulation analysis of the cross wedge rolling process with different combinations of process parameters is carried out through Deform3D software, and the influences of different parameters on die wear is analyzed. Then, the wear-depth data obtained from the simulation analysis are imported into MATLAB software, and the GA algorithm is used to optimize the BP neural network, while the BAS algorithm is chosen to optimize the output data. Finally, the accuracy of the algorithm optimization is verified through experiments and simulations. The research results can provide theoretical guidance and technical support for die-wear behaviors.

\section{The Establishment of Wear Model and Simulation Analysis}

At present, there are three most practical wear-design calculation models and methods that have been verified by experiments: the Archard Model, represented by British Professor J.F. Archard [23]; the Bayer model, represented by American professor R.G. Bayer [24]; and the Kragelsky model, represented by Professor H.B. Kragelsky of the Soviet Union. The Archard wear-calculation method is most widely used in the engineering field. Its equation form is shown in Equation (1):

$$
W=K \frac{L P}{H}
$$

where $W$ is the wear depth, $K$ is the wear coefficient [25], $H$ is the hardness of the mold, $L$ is the relative sliding distance, and $P$ is the contact pressure between the workpiece and the mold.

Due to the influences of temperature on $K$ and $H$ parameters, it is unreasonable to regard these two parameters as constants related to materials in the above model, and it 
will lead to some errors in the actual production. Therefore, Lee and Jou [13] proposed an improved wear model in which $K$ and $H$ are regarded as functions of temperature. It can be expressed as:

$$
W(T)=K(T) \frac{L P}{H(T)}
$$

Among them, the temperature-dependent wear coefficient, $K(T)$, and die hardness, $H(T)$, can be obtained by Equations (3) and (4).

$$
\begin{gathered}
K(T)=[29.29 \times \ln T-168.73] \times 10^{-6} \\
H(T)=9216.4 \times T^{-0.505}
\end{gathered}
$$

During the rolling process, the relative sliding speed, contact pressure, and temperature field change with position and time. Equation (2) can be modified to:

$$
\Delta W_{i j}=K_{i j}(T) \frac{V_{i j} P_{i j}}{H_{i j}(T)} \mathrm{d} t_{j}
$$

Among them, $W_{i j}$ is the wear depth of the mold at the $i$-th position of the $j$-th cycle; the relative sliding velocity, $V_{i j}$, the contact pressure, $P_{i j}$, and the absolute temperature, $T$, can be obtained from simulations by the finite element method.

In the rolling operation, the wear depth of the die at the $i$-th position can be calculated by the following Equation (6).

$$
W_{i}=\sum_{j=1}^{j-n} K_{i j}(T) \frac{V_{i j} P_{i j}}{H_{i j}(T)} d t_{j}
$$

where $n$ is the total steps of the rolling process simulation.

\subsection{Geometric Parameters and Processing Conditions of the Mold}

A roll-type cross wedge rolling method is used to simulate the forming process and abrasive wear. Creo is used to perform 3D modeling of the abrasive tool. Then, a finite element model of cross wedge rolling is established, which is used to analyze the wear behaviors of abrasive tools in the process of cross wedge rolling. The schematic diagram is shown in Figure 1. Because of the symmetry of the cross wedge rolling model, the 1/2 model is used to simulate the calculation to improve the calculation efficiency [26].

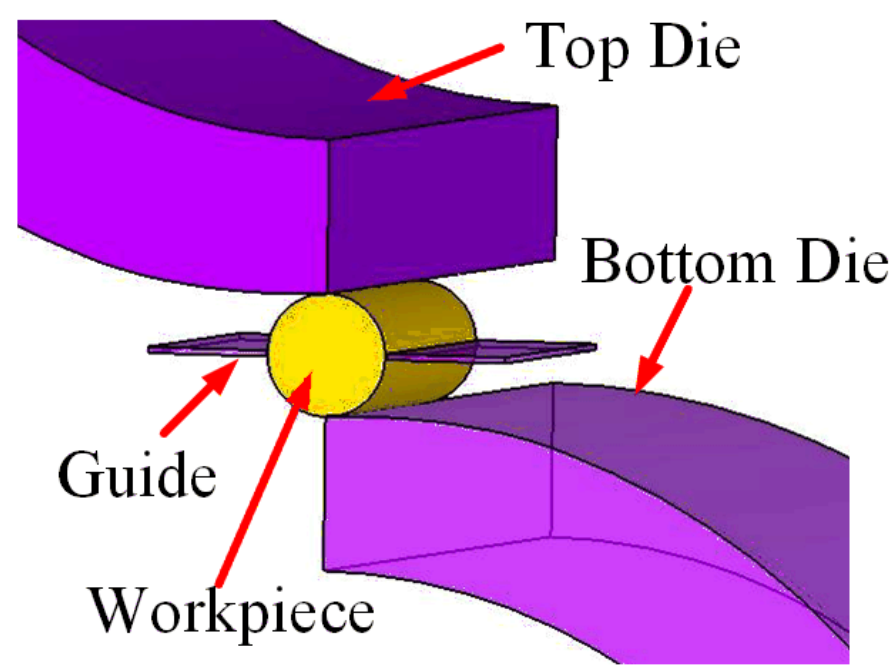

Figure 1. 3D schematic diagram of the mold. 
Ti-6Al-4V alloy and JIS SKD 61 (AISI H13) die steel are used for workpiece and cross wedge rolling die, respectively. Table 1 shows their chemical composition [27].

Table 1. Chemical composition of Ti-6Al-4V alloy and H13 steel (mass fraction, \%).

\begin{tabular}{ccccccccc}
\hline Workpiece & $\mathrm{Al}$ & $\mathrm{V}$ & $\mathrm{Fe}$ & $\mathrm{C}$ & $\mathrm{O}$ & $\mathrm{H}$ & & $\mathrm{Ti}$ \\
Ti-6Al-4V & 6.02 & 3.78 & 0.08 & 0.007 & 0.074 & 0.0082 & $\mathrm{Bal}$ \\
Forging die & $\mathrm{Cr}$ & $\mathrm{V}$ & $\mathrm{Fe}$ & $\mathrm{C}$ & $\mathrm{Mo}$ & $\mathrm{Mn}$ & $\mathrm{Si}$ & $\mathrm{P}$ \\
H13 & 2.08 & 0.84 & $\mathrm{Bal}$ & 0.36 & 1.22 & 0.4 & 0.92 & 0.009 \\
\hline
\end{tabular}

The temperature-related Young's modulus, E [28], thermal conductivity, $K a$ [29], and heat capacity, $C$, of the workpiece material can be obtained by Equation (7), Equation (8) and Equation (9), respectively.

$$
\begin{gathered}
E=104.94-0.052079 \times T \\
K a=0.0131 \times T+6.45 \\
C=2.36+3 \times 10^{-4} \times T+2 \times 10^{-6} \times T^{2}
\end{gathered}
$$

In addition, the material parameters of the $\mathrm{H} 13$ mold are obtained from the work of Hu et al. [30], as shown in Figure 2.

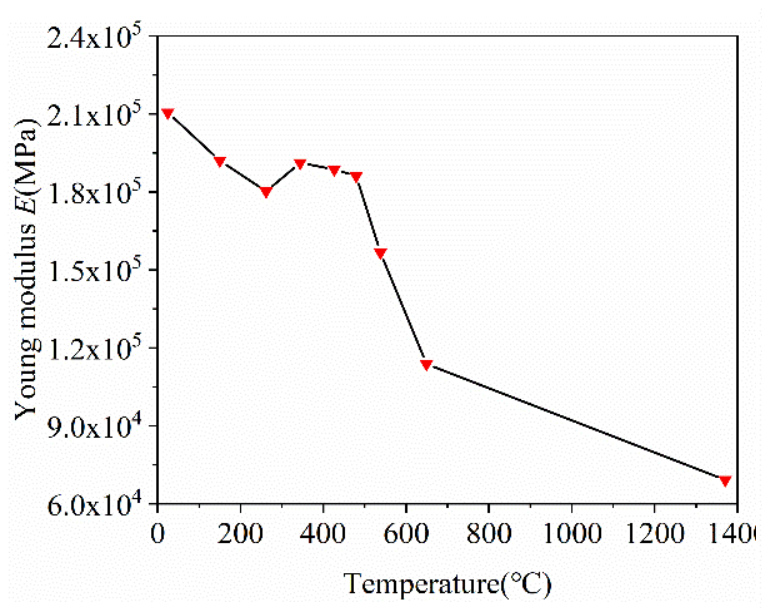

(a)

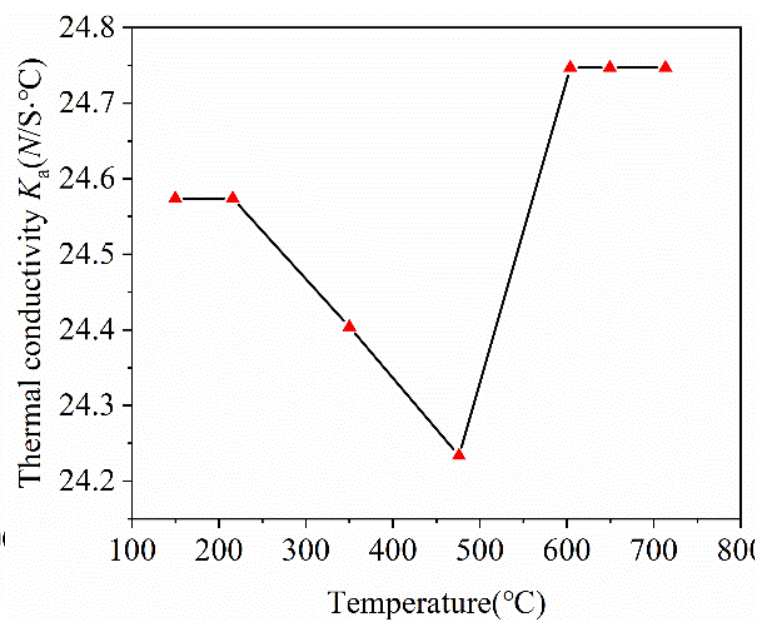

(b)

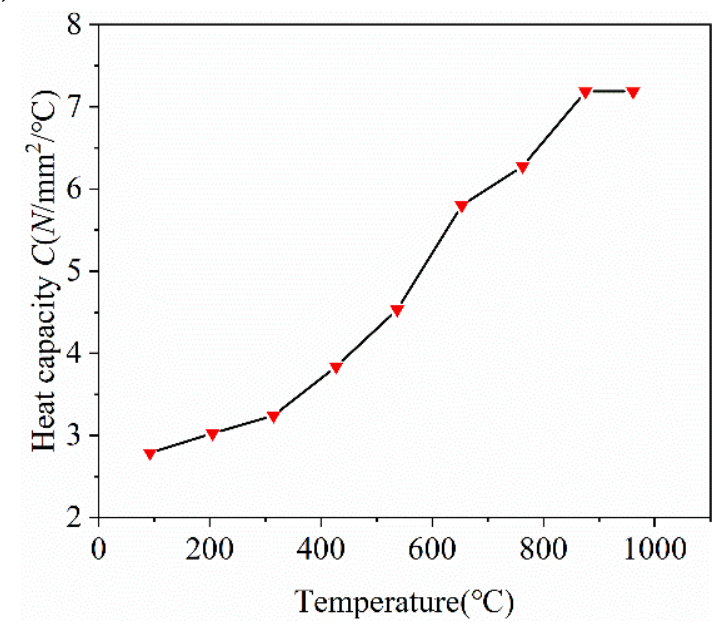

(c)

Figure 2. Material properties of SKD61 roll: (a) Young's modulus; (b) thermal conductivity; (c) heat capacity. 
The main features of the FE model are as follows:

(1) The Johson-Cook constitutive model [31] was established to predict the relationship between strain and stress of Ti-6Al-4V alloy at high temperature.

(2) As shown in Figure 3a, load two restraint planes on both sides of the workpiece to keep the position of the workpiece stable.

(3) Regard the mold and the guide plate as a rigid body and set the roller speed to be constant. In the actual rolling process, the roll speed will fluctuate at the beginning and the end of the rolling process. Roll speed is not considered in this study [32].

(4) The friction model is set as the shear model, and the friction coefficient is set as a constant value. Tetrahedral finite element meshes are used in workpieces and abrasives. In addition, the method of refining mesh is adopted to improve the accuracy of simulation, as shown in Figure $3 b$.

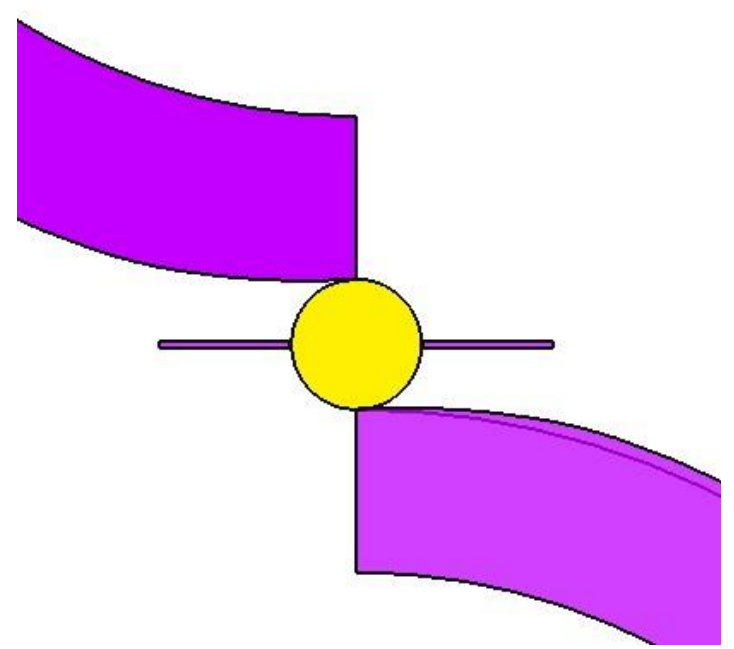

(a)

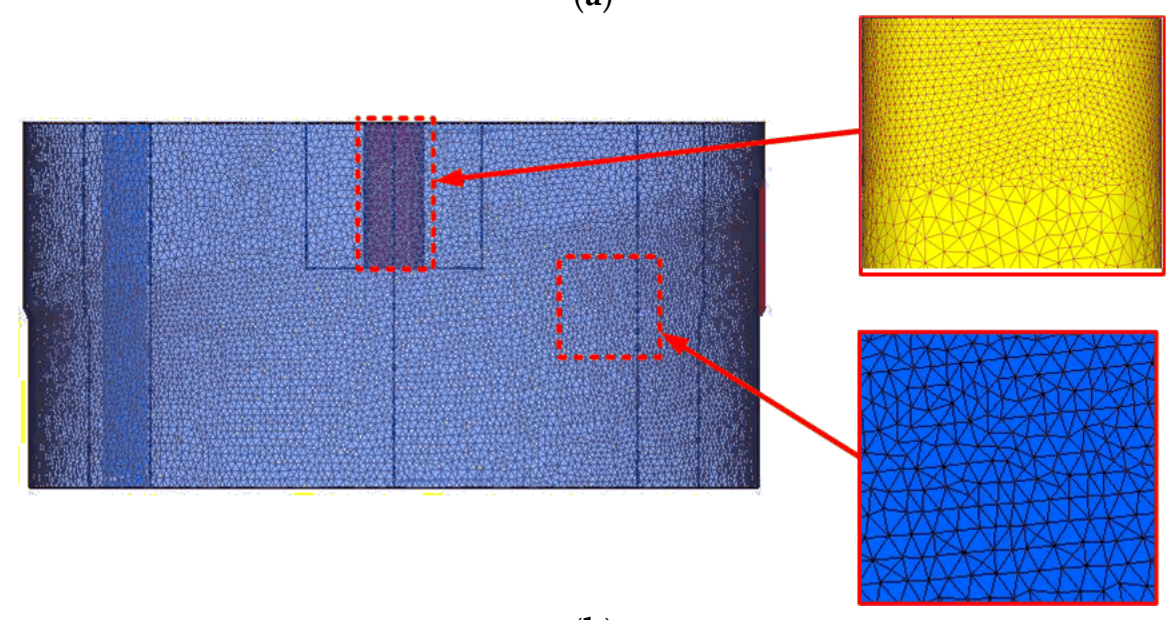

(b)

Figure 3. Local 3D FE model with two constraint planes. (a) Model with guide; (b) local meshing.

In this study, an implicit type of calculation method is used, and each step requires an iterative solution of the equation; using the Lagrangian algorithm, the calculation time is set according to the speed and arc length. In the cross wedge rolling process, if the friction coefficient is too small, it will cause slippage between the mold and the blank. Too much friction will reduce the efficiency or cause the mold to not rotate. Generally, cross wedge rolling is a fast process in practical production. In numerical simulation, it can be considered an ideal process; that is, the friction coefficient does not change.

Table 2 lists the important mechanical and thermal properties of Ti-6Al-4V alloy and SKD61 steel, as well as the process parameters of the workpiece used in the cross wedge 
rolling simulation. In the process of simulation, it is usually necessary to take the average value of several simulations to reduce the error and ensure the accuracy of the simulation.

Table 2. Mechanical and thermal properties of dies and workpieces and main simulation parameters.

\begin{tabular}{|c|c|c|}
\hline Parameters & Forging Die & Workpiece \\
\hline Material & SKD61 & Ti-6Al-4V \\
\hline Young's modulus (MPa) & Figure $2 a$ & Equation (7) \\
\hline Poisson's ratio & 0.3 & 0.342 \\
\hline Density $\left(\mathrm{Kg} / \mathrm{mm}^{3}\right)$ & $7.8 \times 10^{-6}$ & $4.43 \times 10^{-6}$ \\
\hline Thermal conductivity $\left(\mathrm{N} /\left(\mathrm{s}^{\circ} \mathrm{C}\right)\right)$ & Figure $2 b$ & Equation (8) \\
\hline Heat capacity $\left(\mathrm{N} /\left(\mathrm{s} \mathrm{mm}^{2}{ }^{\circ} \mathrm{C}\right)\right)$ & Figure $2 c$ & Equation (9) \\
\hline Emissivity & $0.7[33]$ & $0.7[29]$ \\
\hline $\begin{array}{l}\text { Convection coefficient to environment } \\
\qquad\left(\mathrm{N} /\left(\mathrm{s} \mathrm{mm}^{\circ} \mathrm{C}\right)\right)\end{array}$ & 0.02 & 0.02 \\
\hline $\begin{array}{l}\text { Heat transfer coefficient between } \\
\text { workpiece and die }\left(\mathrm{N} /\left(\mathrm{s} \mathrm{mm}^{\circ} \mathrm{C}\right)\right)\end{array}$ & 5 [29] & \\
\hline Friction factor & 0.9 & \\
\hline Initial temperature of workpiece $\left({ }^{\circ} \mathrm{C}\right)$ & & $810 / 880 / 950$ \\
\hline Initial temperature of dies $\left({ }^{\circ} \mathrm{C}\right)$ & 20 & \\
\hline Environment temperature $\left({ }^{\circ} \mathrm{C}\right)$ & 20 & \\
\hline Step increment control(sec/step) & 0.05 & \\
\hline Number of grids & 200,000 & 200,000 \\
\hline
\end{tabular}

\subsection{Orthogonal Test Design Based on Cross Wedge Rolling Process}

Orthogonal experimental design is an effective mathematical analysis method that can arrange experiments reasonably and analyze experimental factors scientifically. In order to explore the best combination of factors, some representative test conditions were selected from a large number of test conditions, and then the orthogonal table was used for the overall design, comprehensive comparison, and statistical analysis. Through orthogonal experiment design, the best condition can be found through a small number of experiments. Therefore, it has been widely used in scientific research in various fields [34,35].

The processing parameters of cross wedge rolling mainly include rolling temperature, widening angle, forming angle, roll speed, friction coefficient, etc. In this paper, the influences of initial billet temperature, forming angle, broadening angle, section shrinkage, and die speed on cross wedge rolling dies are studied. Based on this, an orthogonal experimental design with five factors and three levels is established. Initial temperature of the blank, forming angle, widening angle, section shrinkage, and rotation speed are used as the five test factors. Three levels of values are found under each factor, and a total of 46 sets of tests are carried out. The factor-level table of the cross wedge rolling process is shown in Table 3.

Table 3. Factor-level table.

\begin{tabular}{cccc}
\hline Factor & Level 1 & Level 2 & Level 3 \\
\hline Initial temperature of & 810 & 880 & 950 \\
workpiece $\left({ }^{\circ} \mathrm{C}\right)$ & 24 & 28 & 32 \\
Forming angle $\left(^{\circ}\right)$ & 8 & 10 & 12 \\
Widening angle $\left({ }^{\circ}\right)$ & 40 & 50 & 60 \\
Section shrinkage $(\%)$ & 8 & 10 & 12 \\
Rotating speed & & & \\
$\left(\mathrm{rad} \cdot \mathrm{min}^{-1}\right)$ & & & \\
\hline
\end{tabular}

According to the factors and levels presented in Table 3, an orthogonal experimental design with five factors and three levels is constructed. The orthogonal table selected is $\mathrm{L}_{46}\left(5^{3}\right)$. The orthogonal test scheme of die wear based on the process parameters of cross wedge rolling is obtained, as shown in Table 4. 
Table 4. Orthogonal test scheme.

\begin{tabular}{|c|c|c|c|c|c|c|}
\hline Number & $\begin{array}{c}\text { Temperature } \\
\left({ }^{\circ} \mathrm{C}\right)\end{array}$ & $\begin{array}{l}\text { Forming Angle } \\
\qquad\left({ }^{\circ}\right)\end{array}$ & $\begin{array}{l}\text { Widening } \\
\left.\text { Angle ( }{ }^{\circ}\right)\end{array}$ & $\begin{array}{c}\text { Section } \\
\text { Shrinkage (\%) }\end{array}$ & $\begin{array}{c}\text { Rotating } \\
\text { Speed } \\
\left(\mathrm{rad} \cdot \min ^{-1}\right)\end{array}$ & $\begin{array}{c}\text { Die-Wear } \\
\text { Depth }(\mathrm{mm})\end{array}$ \\
\hline 1 & 810 & 32 & 10 & 55 & 10 & $8.55 \times 10^{-5}$ \\
\hline 2 & 880 & 28 & 12 & 60 & 10 & $2.32 \times 10^{-5}$ \\
\hline 3 & 880 & 24 & 10 & 55 & 8 & $2.32 \times 10^{-5}$ \\
\hline 4 & 880 & 32 & 12 & 55 & 10 & $3.45 \times 10^{-5}$ \\
\hline 5 & 880 & 24 & 10 & 55 & 12 & $1.2 \times 10^{-5}$ \\
\hline 6 & 880 & 28 & 8 & 60 & 10 & $2.25 \times 10^{-5}$ \\
\hline 7 & 880 & 28 & 10 & 50 & 8 & $1.87 \times 10^{-5}$ \\
\hline 8 & 950 & 28 & 10 & 50 & 10 & $1.38 \times 10^{-5}$ \\
\hline 9 & 810 & 24 & 10 & 55 & 10 & $2.04 \times 10^{-5}$ \\
\hline 10 & 880 & 24 & 10 & 60 & 10 & $2.05 \times 10^{-5}$ \\
\hline 11 & 880 & 28 & 10 & 60 & 8 & $2.22 \times 10^{-5}$ \\
\hline 12 & 880 & 28 & 10 & 55 & 10 & $3.05 \times 10^{-5}$ \\
\hline 13 & 950 & 28 & 10 & 55 & 8 & $1.31 \times 10^{-5}$ \\
\hline 14 & 880 & 28 & 10 & 55 & 10 & $2.5 \times 10^{-5}$ \\
\hline 15 & 880 & 28 & 8 & 55 & 8 & $1.26 \times 10^{-5}$ \\
\hline 16 & 810 & 28 & 10 & 55 & 12 & $6.22 \times 10^{-5}$ \\
\hline 17 & 810 & 28 & 12 & 55 & 10 & $7.65 \times 10^{-5}$ \\
\hline 18 & 880 & 32 & 10 & 55 & 12 & $2.01 \times 10^{-5}$ \\
\hline 19 & 950 & 28 & 10 & 60 & 10 & $1.42 \times 10^{-5}$ \\
\hline 20 & 880 & 28 & 10 & 60 & 12 & $2.05 \times 10^{-5}$ \\
\hline 21 & 880 & 28 & 10 & 55 & 10 & $2.55 \times 10^{-5}$ \\
\hline 22 & 880 & 24 & 8 & 55 & 10 & $2.77 \times 10^{-5}$ \\
\hline 23 & 880 & 32 & 10 & 50 & 10 & $3.05 \times 10^{-5}$ \\
\hline 24 & 880 & 32 & 10 & 60 & 10 & $1.49 \times 10^{-5}$ \\
\hline 25 & 880 & 24 & 12 & 55 & 10 & $1.92 \times 10^{-5}$ \\
\hline 26 & 810 & 28 & 10 & 50 & 10 & $6.52 \times 10^{-5}$ \\
\hline 27 & 950 & 28 & 12 & 55 & 10 & $2.38 \times 10^{-5}$ \\
\hline 28 & 880 & 28 & 10 & 55 & 10 & $3 \times 10^{-5}$ \\
\hline 29 & 950 & 32 & 10 & 55 & 10 & $2.25 \times 10^{-5}$ \\
\hline 30 & 880 & 32 & 8 & 55 & 10 & $1.83 \times 10^{-5}$ \\
\hline 31 & 880 & 28 & 8 & 55 & 12 & $3.13 \times 10^{-5}$ \\
\hline 32 & 880 & 28 & 12 & 55 & 8 & $1.92 \times 10^{-5}$ \\
\hline 33 & 810 & 28 & 10 & 60 & 10 & $6.56 \times 10^{-5}$ \\
\hline 34 & 810 & 28 & 8 & 55 & 10 & $7.65 \times 10^{-5}$ \\
\hline 35 & 880 & 28 & 8 & 50 & 10 & $2.29 \times 10^{-5}$ \\
\hline 36 & 950 & 28 & 10 & 55 & 12 & $1.67 \times 10^{-5}$ \\
\hline 37 & 880 & 28 & 10 & 55 & 10 & $1.88 \times 10^{-5}$ \\
\hline 38 & 880 & 32 & 10 & 55 & 8 & $2.03 \times 10^{-5}$ \\
\hline 39 & 880 & 28 & 10 & 50 & 12 & $2.12 \times 10^{-5}$ \\
\hline 40 & 880 & 28 & 12 & 55 & 12 & $2.64 \times 10^{-5}$ \\
\hline 41 & 950 & 24 & 10 & 55 & 10 & $1.72 \times 10^{-5}$ \\
\hline 42 & 950 & 28 & 8 & 55 & 10 & $2 \times 10^{-5}$ \\
\hline 43 & 880 & 28 & 10 & 55 & 10 & $2.78 \times 10^{-5}$ \\
\hline 44 & 880 & 28 & 12 & 50 & 10 & $2.75 \times 10^{-5}$ \\
\hline 45 & 880 & 24 & 10 & 50 & 10 & $1.8 \times 10^{-5}$ \\
\hline 46 & 810 & 28 & 10 & 55 & 8 & $6.55 \times 10^{-5}$ \\
\hline
\end{tabular}

The simulation results of mold-wear depth and rolling force under certain conditions are shown in Figure 4. As can be seen from Figure 4a, the distribution trend of wear on the die after rolling shows that, generally, the most serious areas of wear are concentrated on the inclined plane and right-angle edge line of the main wedge, and the wear depth is uneven. The resulting curve of rolling force is shown in Figure $4 \mathrm{~b}$. In the whole rolling process, the die is subjected to minimal axial force, while radial force and tangential force are greater [36]. In the wedging section, the wedge-shaped die gradually enters the bar, 
and the bar keeps deforming. The deformation resistance inside the bar makes the load of the wedge-shaped die increase continuously in both directions. Because the deformation is severe and over a short period time, the die load increases faster. This results in an increase in the depth of wear. After entering the broadened section, the radial force fluctuates in a small range. In these two stages, the tangential force is always greater than the radial force, indicating that the axial extension of the rolled piece is more obvious than the radial compression.

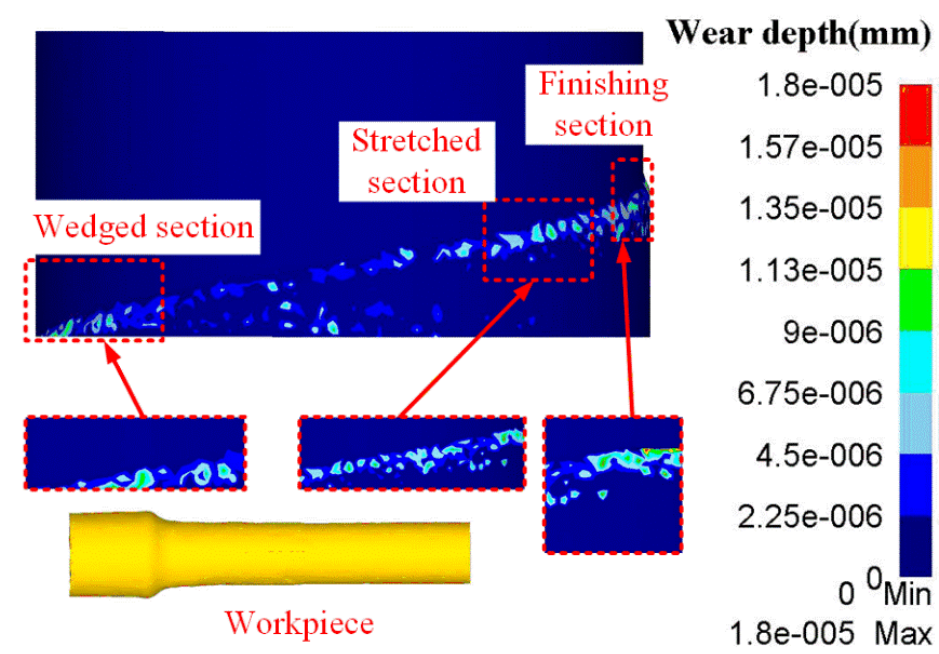

(a)

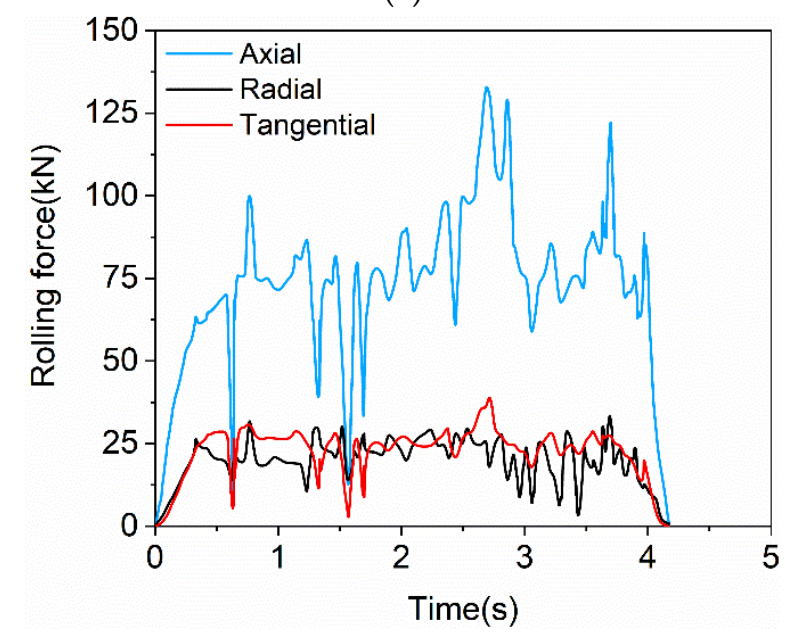

(b)

Figure 4. Cloud chart of wear depth under the conditions of: $\mathrm{T}=880{ }^{\circ} \mathrm{C}$; forming angle, $28^{\circ}$; broadening angle, $10^{\circ}$; section shrinkage, $55 \%$; and rotating speed, $10 \mathrm{rad} / \mathrm{min}$. (a) Wear depth; (b) rolling force.

Figure 5 shows the temperature changes in the die during rolling. As can be seen from Figure $5 \mathrm{a}$, the temperature in the area near the main wedge edge is relatively high when rolling is completed. In order to further study the temperature changes at the hard-worn edges, point tracking is carried out for one point on the edges and two points at other positions on the die, as shown in Figure 5b. The temperature changes at the three tracked points on the main wedge clearly show that the temperature changes at the edge of the wedge are the most dramatic, increasing by $52{ }^{\circ} \mathrm{C}$ at most. In the short time of contact between the main wedge and the rolled piece, the temperature of the contact point on the edge rises sharply, and after the contact part is separated from the rolled piece, the temperature drops slowly, and the rate of change becomes less and less. Lowering the rolling temperature increases the rolling force, which also adds the wear of the abrasion [37]. 


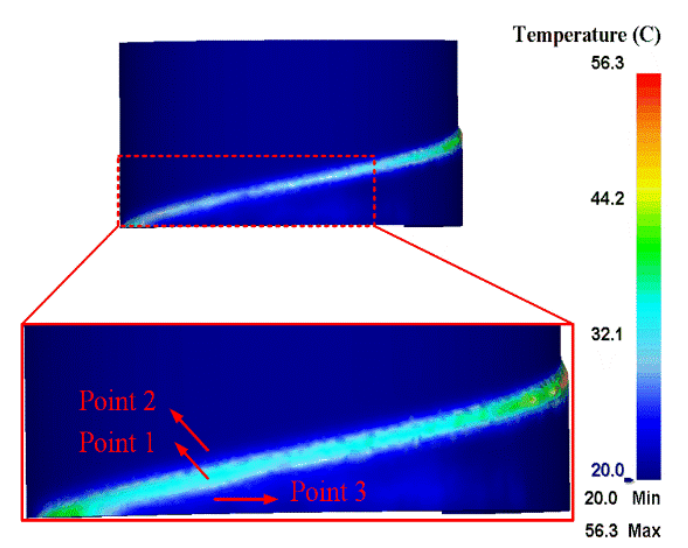

(a)

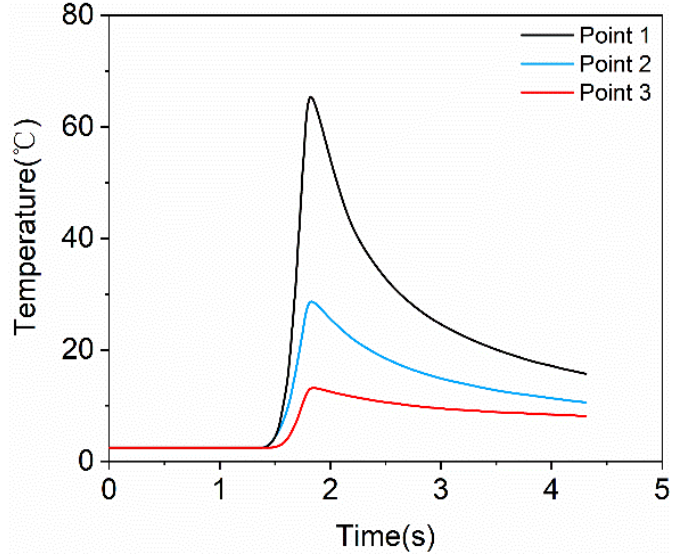

(b)

Figure 5. Cloud chart of temperature changes under the conditions of: $\mathrm{T}=880{ }^{\circ} \mathrm{C}$; forming angle, $28^{\circ}$; broadening angle, $10^{\circ}$; section shrinkage, 55\%; and rotating speed, $10 \mathrm{rad} / \mathrm{min}$. (a) Temperature changes; (b) point tracking.

From the simulations of the 15th and 32nd groups in Table 4, when other conditions are constant, the wear depth increases with the increase in the widening angle. This is due to the increase in the widening angle, which makes the mold shorter. The die squeezes more material radially and axially at the same time, which increases the rolling force, as shown in Figure 6. Therefore, the greater the widening angle, the greater the wear depth.

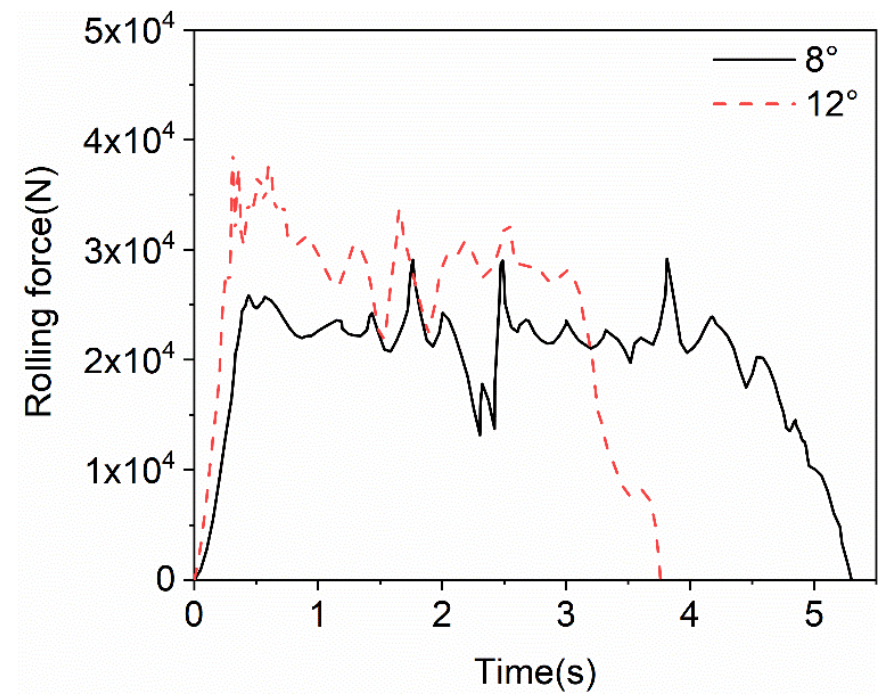

Figure 6. Rolling-force curve at different widening angles.

The forming angle has a significant effect on the rolling force, and the rolling force affects the wear depth. According to the data of the 3rd and 38th groups in Table 4, an increase in the forming angle reduces wear depth. This is due to the increase in the forming angle. When the blank is in the deformation zone, the axial metal flow increases, and the radial-direction metal material flow decreases so that the radial resistance decreases and the rolling force decreases, as shown in Figure 7. Therefore, an increase in the forming angle reduces the overall wear depth. 


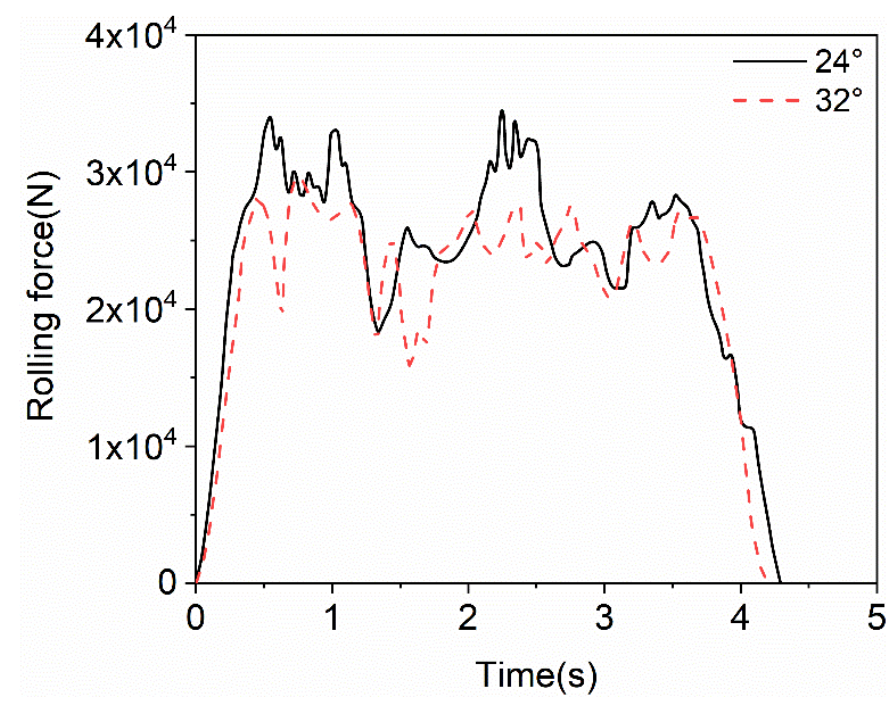

Figure 7. Rolling-force curve at different forming angles.

From the 20th and 39th groups of data in Table 4, it can be seen that when other processing parameters are constant, an increase in the section shrinkage leads to a decrease in the depth of wear. This is because as the section shrinkage increases, the wedge depth of the die increases, which increases the fluidity of the metal in the axial direction. The change in rolling force with section shrinkage is shown in Figure 8.

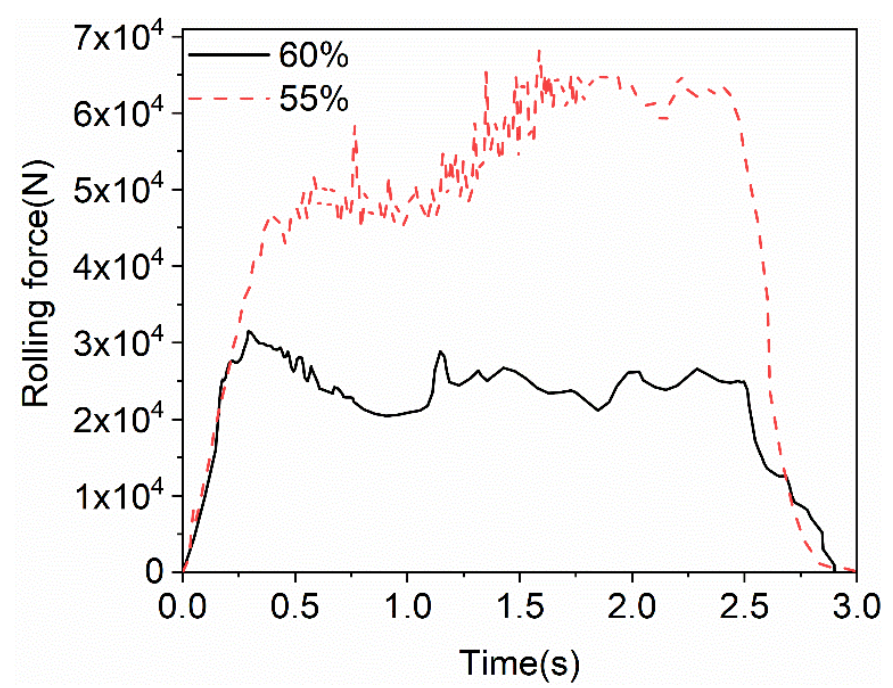

Figure 8. Rolling-force curve at different section shrinkage.

The faster the rotation speed of the die, the more metal material that can be extruded per unit of time; thus, the rolling force increases. With a slower rotation speed, the contact time with the workpiece is longer, more heat is exchanged between the workpieces, and the hardness of the mold decreases due to the absorption of more heat. According to the data in the 16th and 46th groups in Table 4, after combining the two factors, the wear depth decreases with an increase in the speed. This also shows that the influence of temperature on the depth of wear is greater than that of speed. The change in rolling force with speed is shown in Figure 9. 


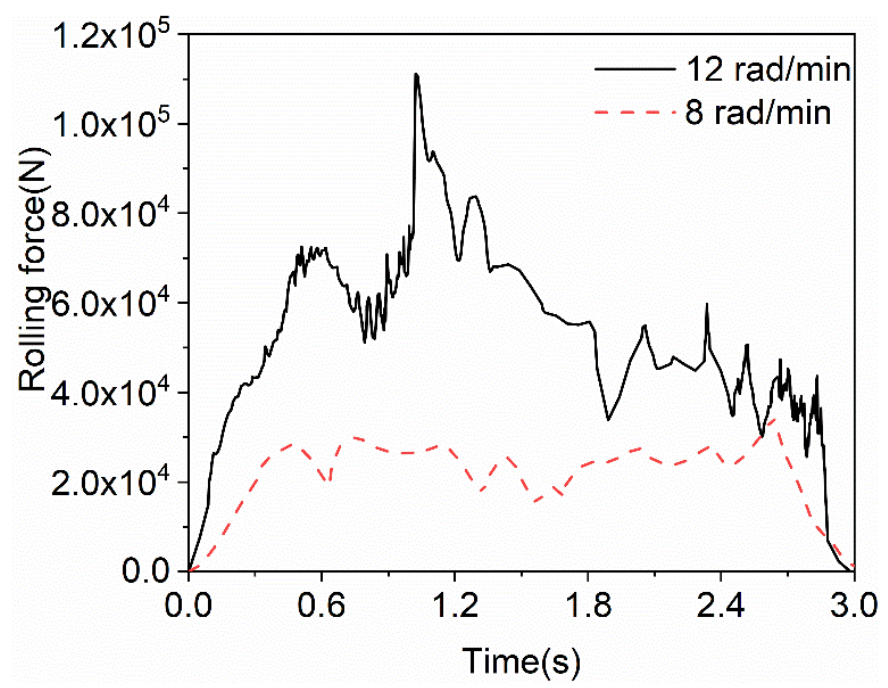

Figure 9. Rolling-force curve at different speeds.

\subsection{Response Surface Analysis}

Figure 10 shows the correlation of mold-wear depth prediction. It can be seen from Figure 10 that the fitting degree of this model is good, and the fitting error is small, which indicates that the established response surface model achieves a decent prediction performance for relevant parameters.

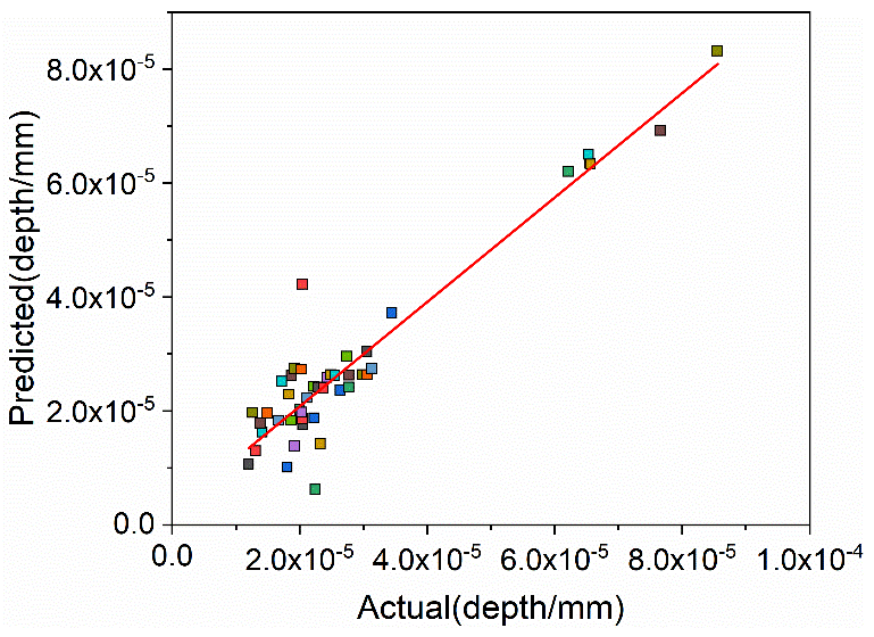

Figure 10. Correlation of wear-depth prediction.

Figure 11 shows the response surface of wear depth changing with temperature, forming angle, broadening angle, section shrinkage, and die speed. It can be seen from Figure $11 \mathrm{a}$ that when forming at a temperature below $880^{\circ} \mathrm{C}$, the greater the shape angle, the greater the wear depth. When the forming angle is $32^{\circ}$ and the billet temperature is $810^{\circ} \mathrm{C}$, the wear depth reaches the maximum value of $8.55 \times 10^{-5} \mathrm{~mm}$. When the temperature is above $880^{\circ} \mathrm{C}$, the wear degree decreases with the increase in the forming angle. This shows that there is an interaction between these two parameters. 
Factor Coding: Actual

Design Points:

Above Surface

Below Surface

$1.2 \mathrm{E}-05 \square 8.55 \mathrm{E}-05$

$\mathrm{X} 1=\mathrm{A}$ : Temperature

$\mathrm{X} 2=\mathrm{B}$ : Forming angle

Actual Factors

C: Widening angle $=10$

D: Section shrinkage $=55$

E: Rotating speed $=10$

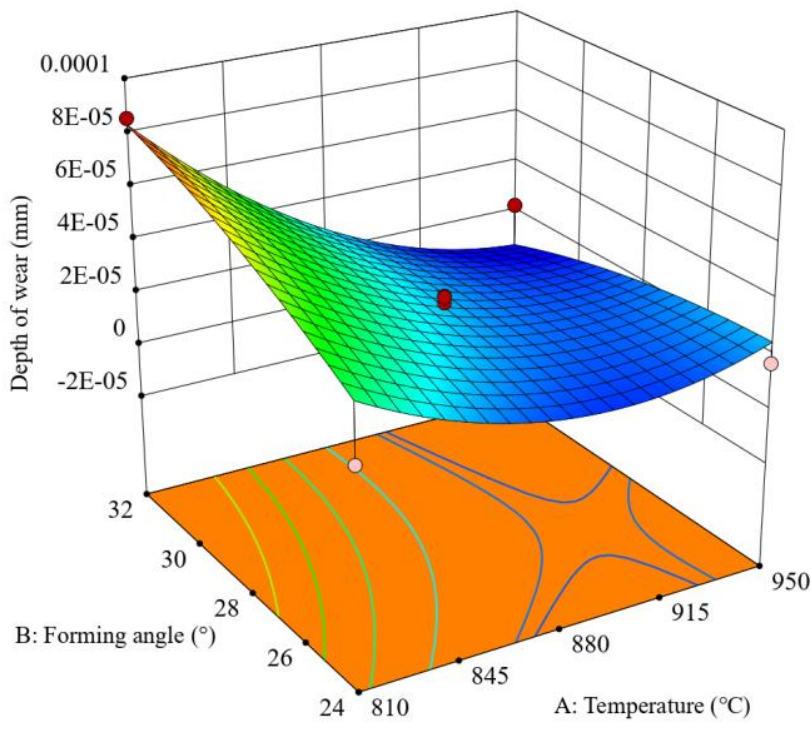

(a)

Factor Coding: Actua

Design Points:

Above Surface

Below Surface

$1.2 \mathrm{E}-05 \square$ 8.55E-05

$\mathrm{X} 1=\mathrm{A}:$ Temperature $\mathrm{X} 2$ = C: Widening angle

Actual Factor

B: Forming angle $=28$

D: Section shrinkage $=55$

E: Rotating speed $=10$

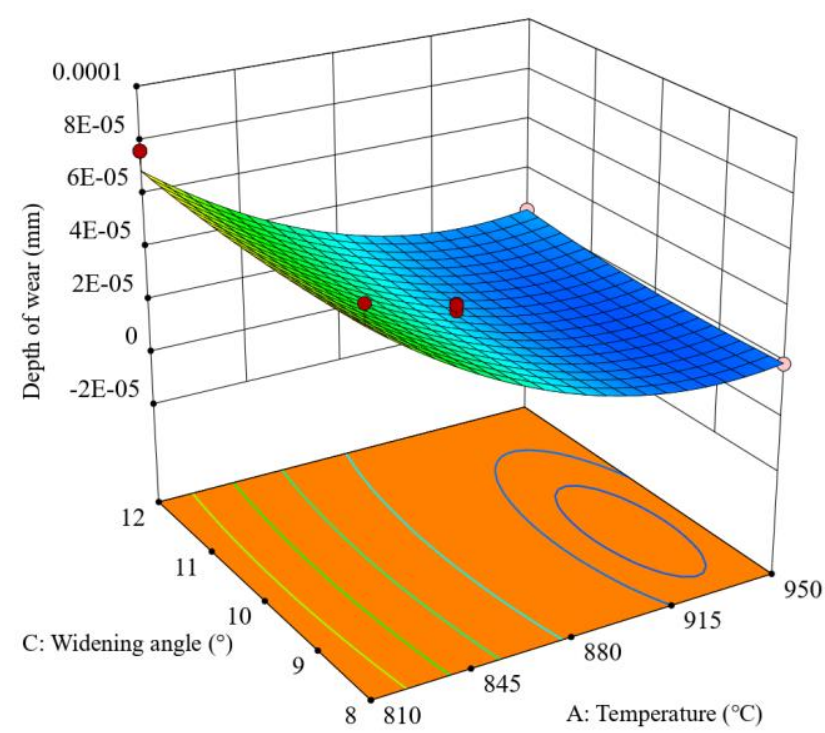

(b)

Figure 11. Cont. 
Factor Coding: Actual Design Points:

Above Surface

Below Surface

$1.2 \mathrm{E}-05 \square 8.55 \mathrm{E}-05$

$\mathrm{X} 1=\mathrm{A}:$ Temperature

$\mathrm{X} 2=\mathrm{D}$ : Section shrinkage

\section{Actual Factors}

B: Forming angle $=28$

C: Widening angle $=10$

E: Rotating speed $=10$

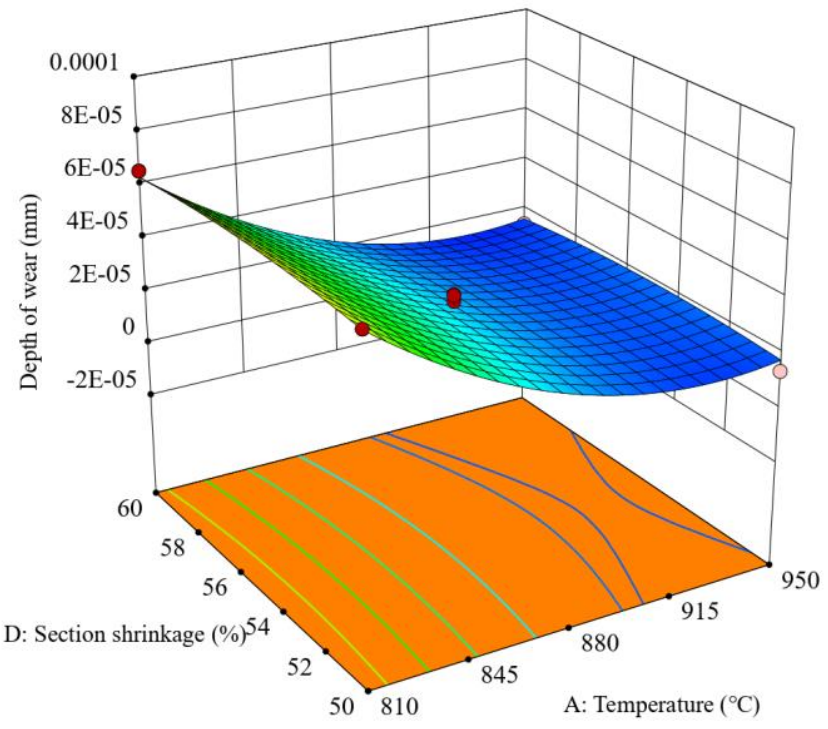

(c)

Factor Coding: Actual

Design Points:

Above Surface

Below Surface

$1.2 \mathrm{E}-05 \square 8.55 \mathrm{E}-05$

$\mathrm{X} 1=\mathrm{A}:$ Temperature

$\mathrm{X} 2=\mathrm{E}$ : Rotating speed

Actual Factors

B: Forming angle $=28$

C: Widening angle $=10$

D: Section shrinkage $=55$

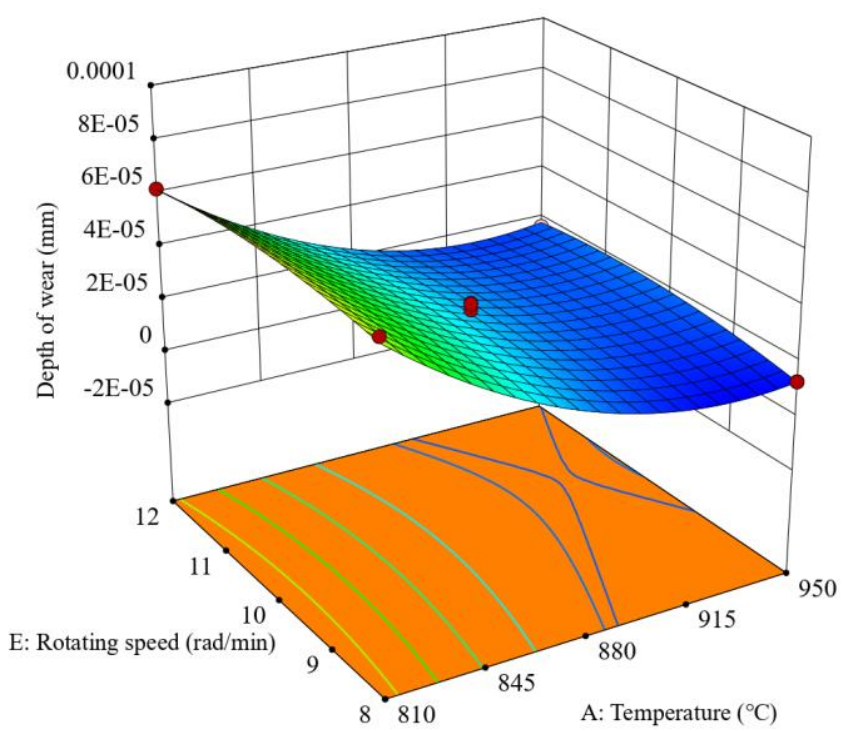

(d)

Figure 11. Response surface of die-wear depth in cross wedge rolling with temperature, forming angle, widening angle, section shrinkage, and rotational speed. (a) Widening angle is $10^{\circ}$, section shrinkage rate is $55.00 \%$, and speed is $10 \mathrm{rad} / \mathrm{min}$. (b) Forming angle is $28^{\circ}$, section shrinkage rate is $55.00 \%$, and speed is $10 \mathrm{rad} / \mathrm{min}$. (c) Forming angle is $28^{\circ}$, widening angle is $10^{\circ}$, and speed is $10 \mathrm{rad} / \mathrm{min}$.(d) Forming angle is $28^{\circ}$, widening angle is $10^{\circ}$, and section shrinkage rate is $55.00 \%$.

When the forming angle is $28^{\circ}$, the section shrinkage rate is $55 \%$, and the speed is $10 \mathrm{rad} / \mathrm{min}$, as shown in Figure 11b. The depth of wear continues to increase with rising temperature. The degree of change of the two parameters does not change significantly with changes in the other processing parameters. By observing the contour distributions in the 
figure, it can be seen that the influence of temperature on the abrasive wear depth is far greater than the spread angle. This rule can also be observed in Figure 11c,d. In Figure 11c, the wear depth decreases rapidly with the increasing forming temperature. However, when the temperature is higher than $880^{\circ} \mathrm{C}$, this trend becomes more gentle, and the wear depth decreases slowly as the temperature rises.

In summary, it can be concluded that the deformation temperature has the greatest influence on the wear depth of the mold, followed by the forming angle, while other parameters have less impact wear depth, and there is an interaction between the forming angle and the deformation temperature. It can be seen that in order to obtain the optimal wear depth, the interaction between process parameters should be reasonably considered, and the influence degree of parameters should be clear, so as to reasonably and effectively improve the utilization rate of the die and reduce its wear depth.

\section{Parameter Optimization Based on BAS-GA-BP Model}

An artificial neural network (ANN) is an intelligent information-processing system with the characteristics of parallel information processing, self-learning, and distributed storage. It has a certain correlation-fault-tolerant ability and is used to solve complex nonlinear problems [38]. The structure of a BP neural network can be divided into three layers, from left to right: input layer, hidden layer, and output layer [39]. The most basic BP network is a single hidden layer structure, and the data in the input layer are variable. For data received from the outside, internal algorithmic operations are performed through the input layer, which are transmitted to the hidden layer. The hidden layer receives the data and performs operations according to the user-selected transfer function, then passing the data to the next layer, and so on [40].

\subsection{BP Neural Network Construction}

The selected input parameters of the sample are initial billet temperature, forming angle, widening angle, section shrinkage, and rotational speed. The values of the five parameter nodes are assigned to the input layer, $X_{1} \sim X_{5}$, and the output layer is the corresponding wear depth. Its network structure is shown in Figure 12.

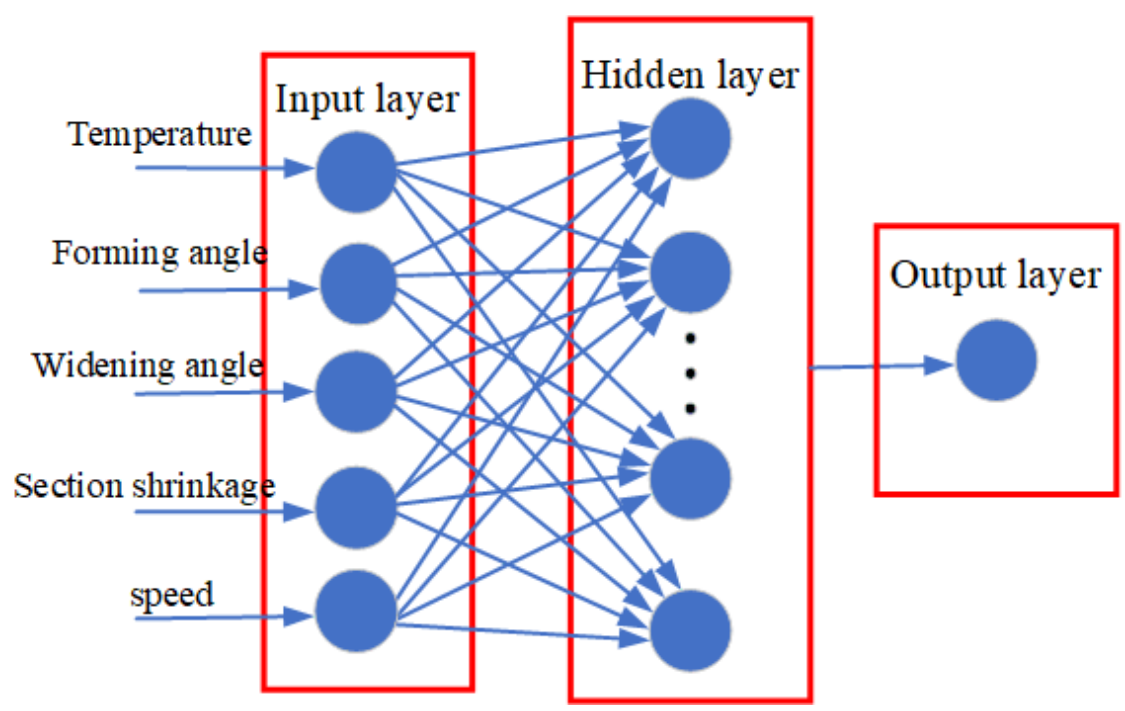

Figure 12. BP network-structure diagram.

In the process of data input, the initial billet temperature, forming angle, widening angle, section shrinkage, and speed of the order of magnitude and unit have significant dif- 
ferences. In order to eliminate the influence of data magnitude on the input-layer function, the sample data should be normalized before input [41], as shown in Equation (10):

$$
X^{\prime}=0.1+0.8 \cdot \frac{X-X_{\min }}{X_{\max }-X_{\min }}
$$

where, $X$ is the input data of the sample; $X_{\max }$ and $X_{\min }$ are the maximum and minimum values in the sample input data, respectively.

Equation (11) is used for inverse normalization processing during data output:

$$
Y^{\prime}=X_{\min }+1.25 \cdot\left(X_{\max }-X_{\min }\right) \cdot(Y-0.1)
$$

where $Y$ is the sample output data; $Y^{\prime}$ is the inverse normalized output data. In order to ensure that the training can achieve the "adaptive" effect and the system error is small, the BP neural network should choose the appropriate training function, learning function, training error, and other parameters. Through trial and error, the Sigmoid function is selected as the activation function, the tansig function is used as the transfer function of the hidden layer, and the purelin function is selected as the node-transfer function for the output layer.

The number of hidden layer nodes is calculated by Equation (12).

$$
l=\sqrt{p+q}+k
$$

where $l$ is the number of nodes in the hidden layer; $p$ is the number of nodes in the output layer; $q$ is the number of nodes in the input layer; and $k$ is the adjustment constant between 1 and 10. Therefore, the value range of $l$ is between 3 and 13. Through the training of different node sample models, the LM optimization algorithm with fast convergence speed and high precision is used to compare the number of nodes of different hidden layers, and the one with the smallest error value is selected as the number of nodes of hidden layers.

In order to verify the prediction results of the model, the average relative error (ARE) and goodness of fit (COD) are taken as the evaluation indexes of the prediction model [42] The lower the average relative error, the better the prediction results of the model. The range of goodness of fit is [0,1], and the calculated value is closer to 1 . This shows that the effect of the prediction model is better, as shown in Equation (13):

$$
\left\{\begin{array}{c}
\text { Are }=\frac{1}{n} \sum_{i=1}^{n}\left|\frac{y_{m, i}-y_{t, i}}{y_{t, i}}\right| \\
\mathrm{COD}=\frac{\left(n \sum_{i=1}^{n} y_{m, i} y_{t, i}-\sum_{i=1}^{n} y_{m, i} \sum_{i=1}^{n} y_{t, i}\right)^{2}}{\left[n \sum_{i=1}^{n} y_{m, i}^{2}-\left(\sum_{i=1}^{n} y_{m, i}\right)^{2}\right]\left[n \sum_{i=1}^{n} y_{t, i}^{2}-\left(\sum_{i=1}^{n} y_{t, i}\right)^{2}\right]}
\end{array}\right.
$$

where $n$ is the number of samples; $y_{m, i}(i=1,2, \ldots, n)$ is the model prediction value of the $i$-th sample; and $y_{t, i}(i=1,2, \ldots, n)$ is the $i$-th sample of the true value of each sample.

\subsection{Goodness-of-Fit Test}

In order to improve the above defects, the genetic algorithm (GA) is used to optimize the BP neural network through MATLAB, which improves the stability and accuracy of the $\mathrm{BP}$ neural network. The trainlm function is called to train the data, and the expected error is set at $0.1 \%$, with the learning rate set at 0.01 . A total of 35 sets of data are used to train the remaining 11 sets of data to ensure that the number of training samples is 2-10 times the connection weight of the network model. The mapminmax function is used to normalize the input and output data, with a value range of $[-1,1]$, and its expression is shown in Equation (11). The maximum number of BP iterations is 3000 , the momentum factor is 0.9 , the increment of learning rate is 1.05 , and the target error is $10^{-5}$. Based on the empirical formula, the number of hidden layers is determined to be six, based on the trial-and-error method. The predicted value of the GA-BP neural network and the predicted value of the BP neural network are shown in Figure 13. It can be seen that the performance of the 
GA-BP algorithm to predict wear depth is better than that of the BP algorithm, with an $5.219 \%$ error, which indicates that the former can predict wear behavior of the die more accurately.

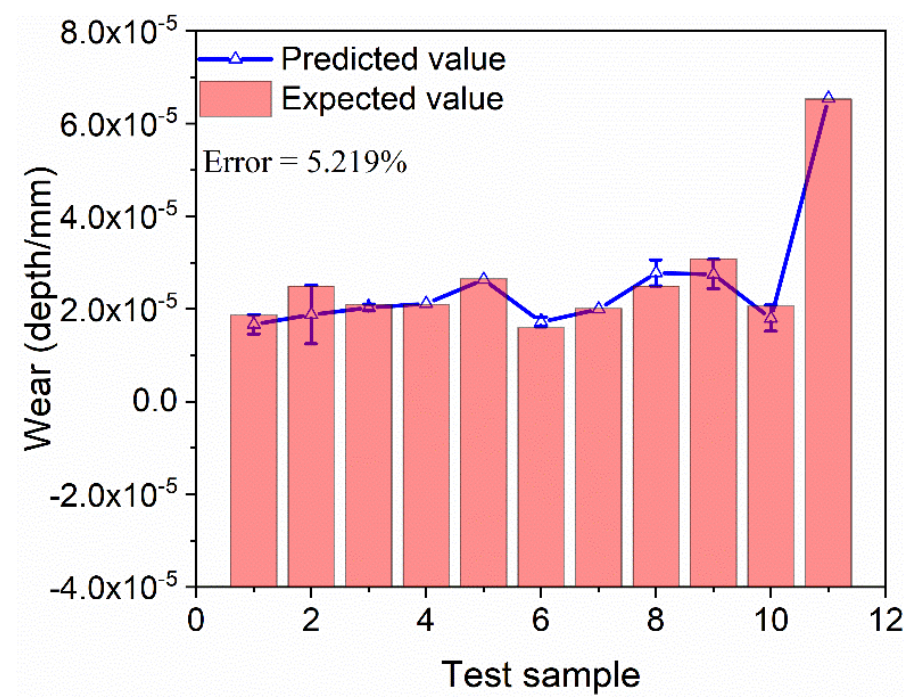

Figure 13. Comparison between experiment and prediction.

\subsection{Establishment of BAS Algorithm}

A random direction vector representing the search behavior of aerial beetle antennae is established, as shown in Equation (14):

$$
\mathrm{b}=\frac{\operatorname{rands}(k, 1)}{\|\operatorname{rands}(k, 1)\|}
$$

where rands is a random function and $k$ is the spatial dimension.

The MSE between the model output and the expected output was taken as the fitness function. The weight and threshold corresponding to the minimum fitness function are the optimal solution. The fitness function is shown in Equation (15).

$$
F=\operatorname{MSE}=\frac{1}{N} \sum_{i=1}^{N}\left(X_{\text {model }, i}-X_{\text {ture }, i}\right)^{2}
$$

where $N$ is the number of training samples; $X_{\text {model }, i}$ is the model output value of the $i$-th sample; and $X_{\text {ture }, i}$ is the actual value of the $i$-th sample.

The length of the beetle antenna, $d^{t}$, and the search step, $\delta^{t}$, are determined, respectively, as shown in Equation (16).

$$
\left\{\begin{array}{c}
d^{t+1}=0.95 d^{t}+c \\
\delta^{t+1}=0.95 \delta^{t}
\end{array}\right.
$$

The length of beetle antenna corresponds to the exploration ability of longicorn beetles in the search space. The length of the beetle antenna should decrease with the continuation of the search time for precise exploration. The beetle search step size is related to the convergence speed, and the initial value of the step size should be adapted to the search space. $\mathrm{c}$ is a constant, and in this study, $c=1$.

According to Equations (17) and (18), the spatial positions of the left and right whiskers of longicarp beetles are calculated, and the fitness functions of the left and right whiskers 
of beetles are compared to update the spatial positions of beetles. In this way, the search of beetles is started, and the optimal solution and the optimal fitness are constantly updated.

$$
\left\{\begin{array}{l}
x_{r t}=x^{t}+d^{t} b \\
x_{1 t}=x^{t}-d^{t} b
\end{array}\right.
$$

where $x^{t}$ is the spatial position of the beetle at $t$-time searching; $x_{r t}$ is the spatial position of the right whisker of the beetle at $t$-time searching; $x_{1 t}$ is the spatial position of the left whisker of the beetle at $t$-time searching; and $d_{t}$ is the whisker length of the beetle at $t$-time searching.

$$
x^{t+1}=x^{t}-\delta^{t} b \operatorname{sign}\left[f\left(x_{r t}\right)-f\left(x_{1 t}\right)\right]
$$

where $x^{t+1}$ is the spatial position of the beetle at $t+1$ time searching; $x^{t}$ is the spatial position of the beetle at the time search, $t ; \delta^{t}$ is the step size of the $t$-th beetle detection movement; sign is a sign function; and $f$ is a function of fitness.

The optimal solution is determined. If the MSE is less than the predetermined accuracy or the number of iterations meets the requirements, the beetle search stops. At this time, the solution corresponding to the optimal fitness is the optimal solution, which is used to initialize the weights and thresholds of the BP network.

The specific process of the BAS-GA-BP prediction model is shown in Figure 14.

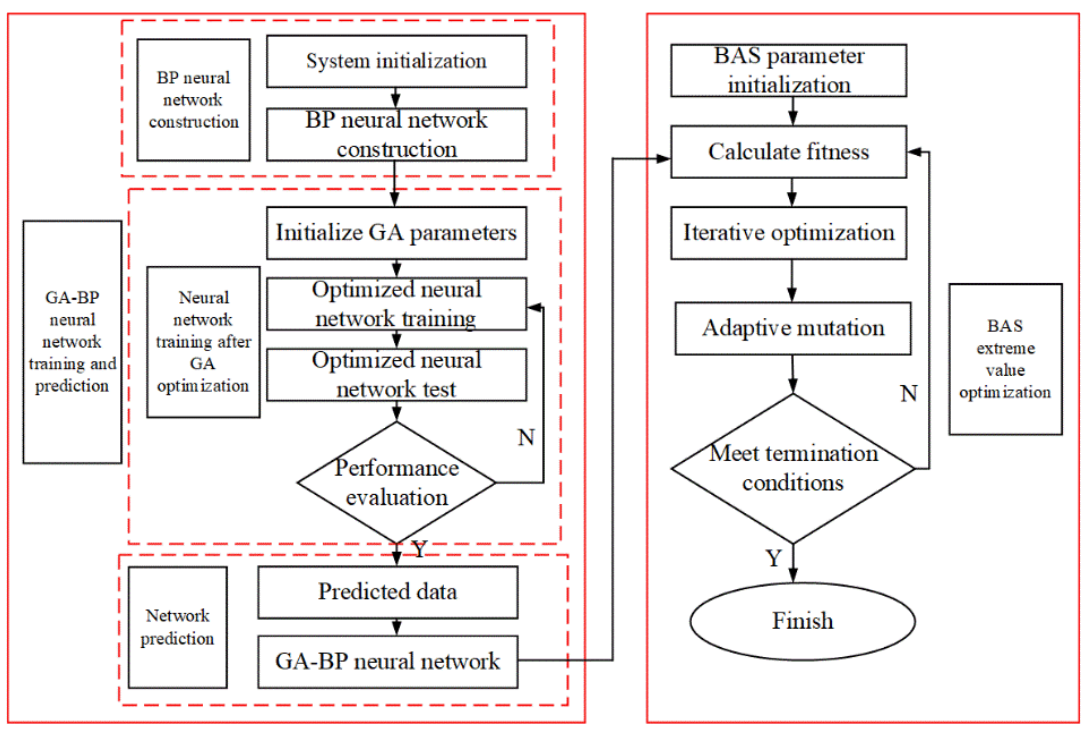

Figure 14. BAS (beetle antennae search)-GA (genetic algorithm)-BP (back propagation neural network) algorithm flow chart.

The BAS algorithm is used for optimization. As can be seen from Figure 15, when BAS iteration reaches the 30th step, the fitness value of the optimal particle tends to be stable, and the result is $6.252 \times 10^{-7}$. The result of training has high accuracy. The optimal parameters of the cross wedge rolling process are as follows: initial billet temperature, $\mathrm{T}=813.68^{\circ} \mathrm{C}$; forming angle, $24.06^{\circ}$; broadening angle, $10.24^{\circ}$; section shrinkage, $53.5 \%$; speed, $11.97 \mathrm{rad} / \mathrm{min}$. 


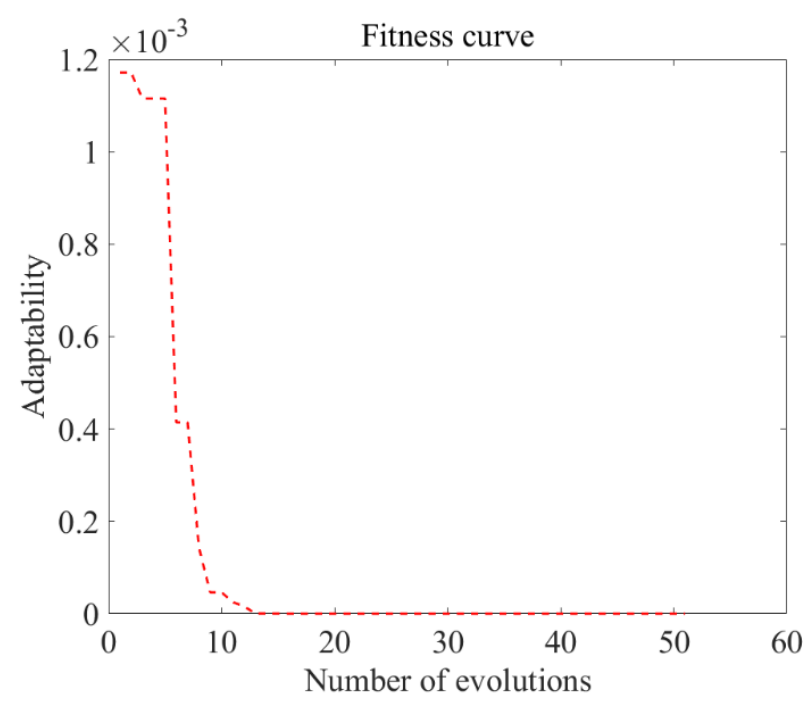

Figure 15. BAS-GA-BP algorithm training process.

\subsection{Simulation and Experimental Validation}

The optimized parameters are substituted into the finite element calculation. The simulation results are shown in Figure 16.

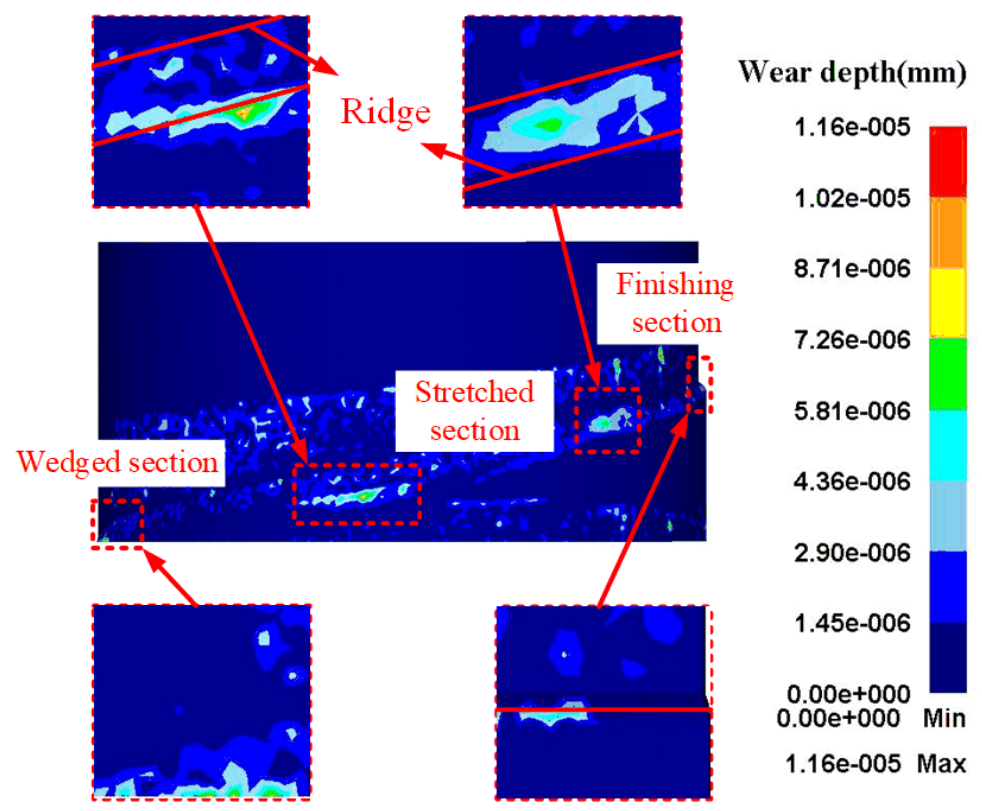

Figure 16. Simulation wear distribution diagram after optimization.

It can be seen from Figure 15 that the maximum wear value is $1.16 \times 10^{-5}$, which is smaller than the maximum wear value before optimization $\left(1.2 \times 10^{-5}\right)$. Moreover, the wear depth is relatively uniform. The wear depth is larger only at the beginning of the wedging section and the broadening section. At the other stages, the wear is distributed evenly on the wedge-shaped bevels and edges.

Figure 17 is the temperature-change diagram of the simulation results of the optimal parameters. As can be seen from Figure 17, during the rolling process, temperature changes are concentrated on the wedge-shaped edges and wedge-shaped bevels. Taking three points at the same position for point tracking, the temperature change decreases significantly compared to before optimization. The maximum temperature rise $\left(21.24^{\circ} \mathrm{C}\right)$ is less than that before optimization $\left(52^{\circ} \mathrm{C}\right)$. This results in a small change in the hardness of the die, which reduces wear. 


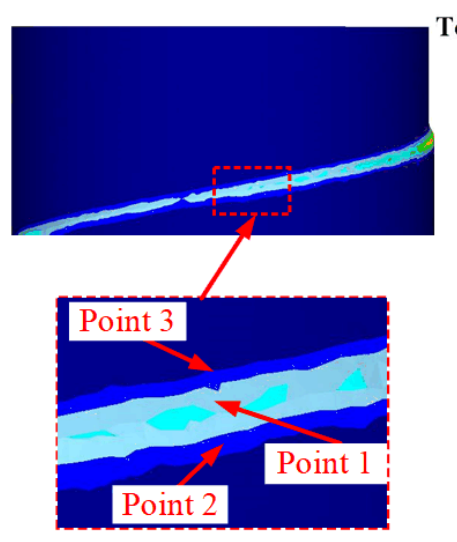

(a)

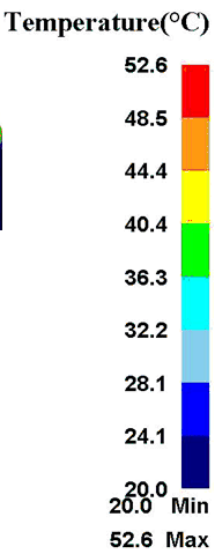

52.6 Max

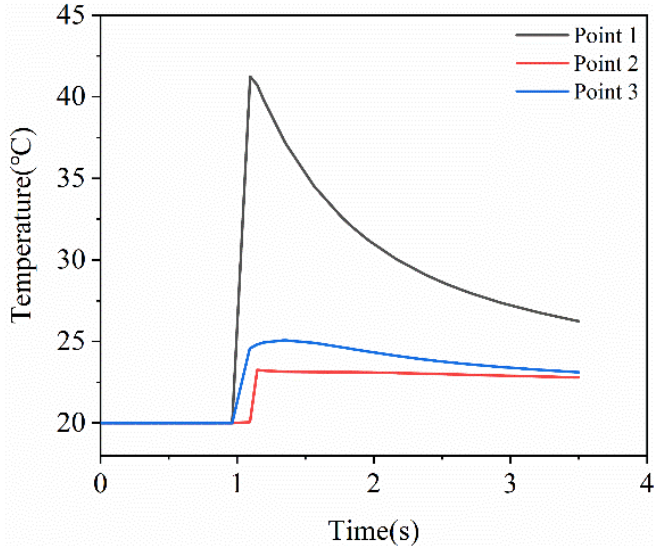

(b)

Figure 17. Temperature-variation diagram of simulation results of optimal parameters. (a) Temperature nephogram, (b) temperature changes.

An H-500 cross wedge rolling mill is used in the test, and the process parameters obtained after BAS optimization are verified in actual production, as shown in Figure 18. As shown in Figure 18, the wear position of the die after rolling is mainly concentrated on the wedge-shaped edges, which is consistent with the simulation results.

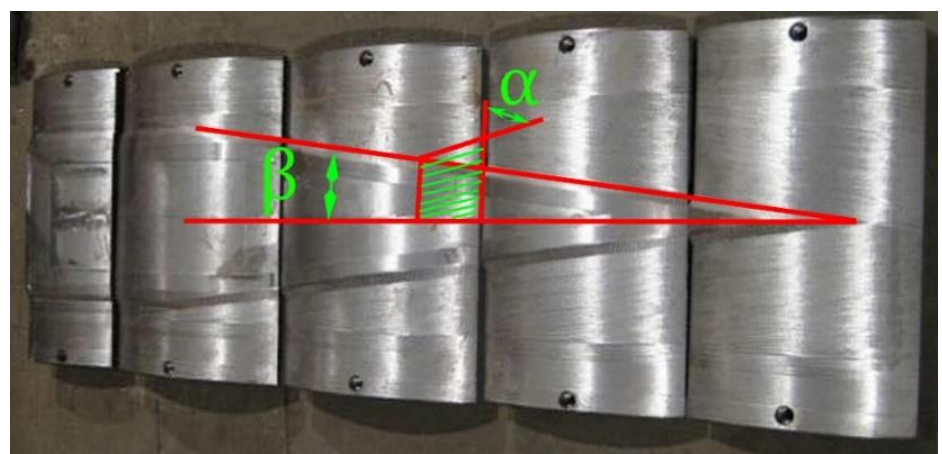

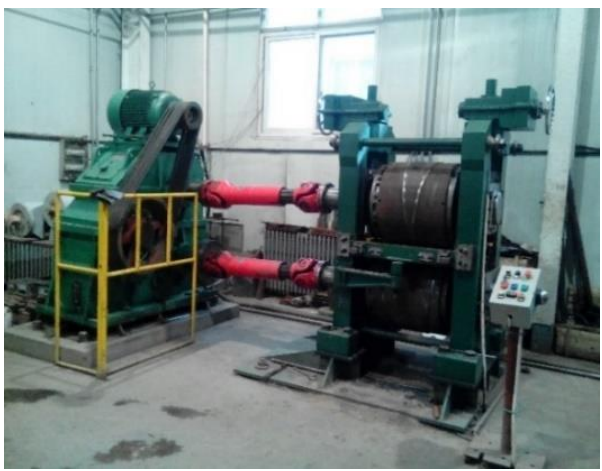

(b) (a)

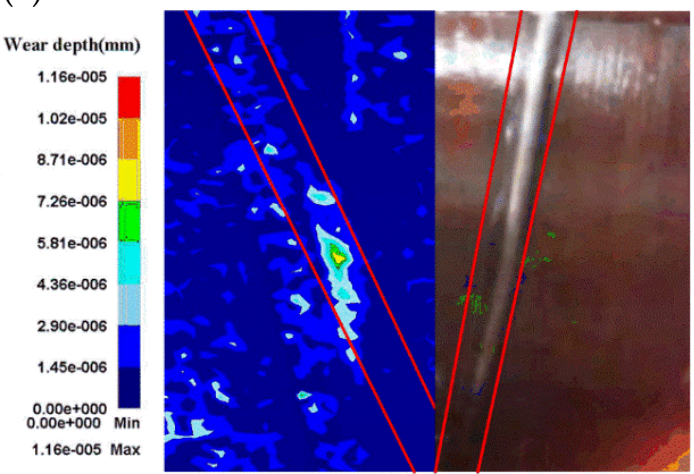

(c)

Figure 18. Test equipment:(a) cross wedge rolling die, $\alpha$-forming angle; $\beta$ - widening angle; (b) H-500 cross wedge mill; (c) die after rolling.

During the test, rolling force is difficult to measure, so the rolling moment is used instead. The resistors are attached directly to the surface at $45^{\circ}$ to the axis. To compensate for the effects caused by bending, the resistors are attached in two groups in symmetrical positions and led to the strain gauge via a slip ring. Figure 19 shows the test-measured rolling torque compared to the simulated torque. As can be seen in Figure 19, the test and simulated values of the rolling torque match in most cases, with only some conditions under which the simulated value is lower than the test value. This is because it is an ideal 
process during the finite element simulation and does not take into account factors such as changes in friction.

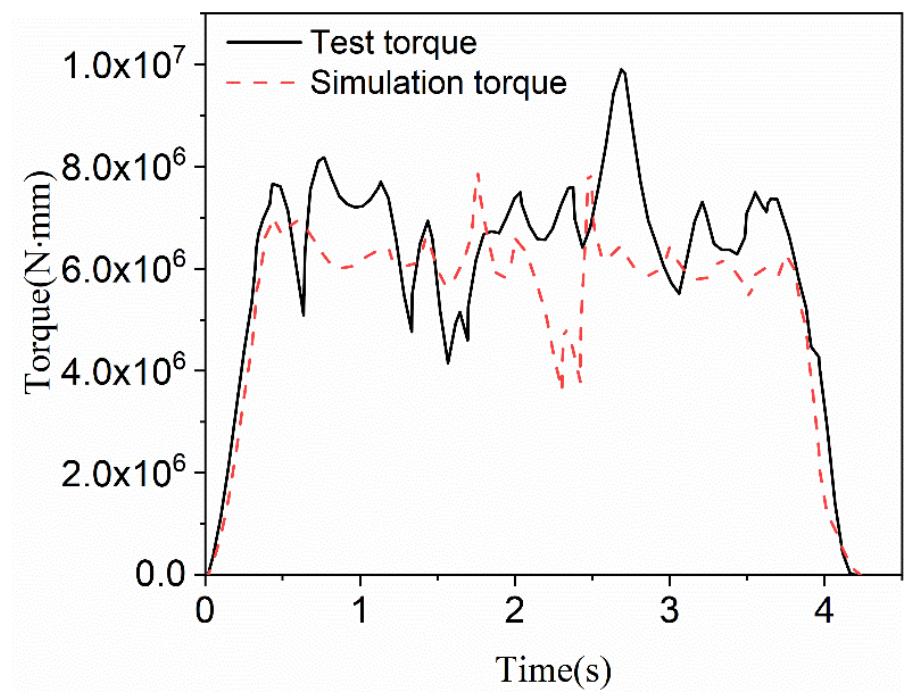

Figure 19. Comparison of test and simulation values of rolling torque.

\section{Conclusions}

Based on the Archard die wear theory, the die wear model of TC4 titanium alloy CWR is established. The die-wear characteristics during CWR of Ti-6Al-4V titanium alloy are revealed by the finite element method. The following conclusions are obtained:

1. Through finite element analysis, it is found that the area with the most serious wear on the die after rolling is basically concentrated on the inclined plane of wedges and the edge line of right angle. Wear depth is affected by the machining parameters, and the influence law is as follows: The wear depth increases with an increase in temperature and widening angle. It decreases with an increase in forming angle, section shrinkage, and rotating speed.

2. A further conclusion is drawn through response surface analysis. Among all the deformation parameters, deformation temperature has the greatest influence on the wear depth of the die, followed by forming angle, while the other parameters have little effect on wear depth, and there is an interaction between forming angle and the deformation temperature.

3. Through use of the GA-BAS-BP algorithm, the parameters that minimize the wear depth are obtained: $\mathrm{T}=813.6845{ }^{\circ} \mathrm{C}$; forming angle, $24.0674^{\circ}$; widening angle, $10.2415^{\circ}$; section shrinkage, $53.5077 \%$; and rotating speed, $11.9768 \mathrm{rad} / \mathrm{min}$. The wear value is $1.16 \times 10^{-5} \mathrm{~mm}$. The accuracy of the GA-BAS-BP algorithm is verified by comparison with the experiment.

Author Contributions: Z.P., writing—original draft, investigation; H.J., project administration, conceptualization, review and editing, investigation; X.H., review and editing, investigation; B.W., project administration, conceptualization; W.X., review and editing; S.W., Check and revise. All authors have read and agreed to the published version of the manuscript.

Funding: This work is supported by the National Natural Science Foundation of China (51905501). This work is also supported by the Tangshan Talent Foundation Innovation Team (20130204D) and funded by the S\&P Program of Hebei (Grant No.19012204Z).

Data Availability Statement: Not applicable.

Conflicts of Interest: The authors declare no conflict of interest. 


\section{References}

1. Huang, X.; Wang, B.; Mu, Y.; Shen, J.; Li, J.; Zhou, J. Investigation on the effect of mandrels on hollow shafts in cross-wedge rolling. Int. J. Adv. Manuf. Technol. 2019, 102, 443-455. [CrossRef]

2. Zhu, S.; Peng, W.-F.; Shu, X.-D. Effect of tempering on bonding characteristics of cross wedge rolling 42CrMo/Q235 laminated shafts. J. Iron Steel Res. Int. 2020, 27, 1170-1178. [CrossRef]

3. Pater, Z.; Tomczak, J.; Bulzak, T.; Walczuk-Gagała, P. Novel Damage Calibration Test Based on Cross-Wedge Rolling. J. Mater. Res. Technol. 2021, 13, 2016-2025. [CrossRef]

4. Feng, P.; Yang, C.; Wang, B.; Li, J.; Shen, J.; Yang, X. Formability and microstructure of TC4 titanium alloy hollow shafts formed by cross-wedge rolling with a mandrel. Int. J. Adv. Manuf. Technol. 2021, 114, 365-377. [CrossRef]

5. Meng, X.; Zhang, J.; Xiao, G.; Chen, Z.; Yi, M.; Xu, C. Tool wear prediction in milling based on a GSA-BP model with a multisensor fusion method. Int. J. Adv. Manuf. Technol. 2021, 114, 3793-3802. [CrossRef]

6. Hisakado, T.; Miyazaki, K.; Kameta, A.; Negishi, S. Effects of surface roughness of roll metal pins on their friction and wear char-acteristics. Wear 2000, 239, 69-76. [CrossRef]

7. Iwadoh, S.; Kuwamoto, H.; Sonoda, S. An Investigation about the Mechanism of Work Roll Wear at the Cold Rolling. Tetsu-toHagane 1989, 75, 2059-2066. [CrossRef]

8. Luo, S.; Zhu, D.; Hua, L.; Qian, D.; Yan, S. Numerical analysis of die wear characteristics in hot forging of titanium alloy turbine blade. Int. J. Mech. Sci. 2017, 123, 260-270. [CrossRef]

9. Riemer, O.; Elsner-Dörge, F. Investigation of material removal in vibration polishing of NiCo alloys with millimetre-sized tools. Int. J. Adv. Manuf. Technol. 2017, 92, 541-3122. [CrossRef]

10. Shelke, R.D.; Rafiuddin, S.A. Numerical Simulation and Comparison of Carbide and HSS Tool Wear Rate while Drilling with Difficult to Cut Super Alloy Titanium Based on Archard Model. Int. J. Adv. Eng. Res. Sci. 2018, 5, 265244. [CrossRef]

11. Kang, J.; Park, I.; Jae, J.; Kang, S. A study on a die wear model considering thermal softening: (I) Construction of the wear model. J. Mater. Process. Technol. 1999, 96, 53-58. [CrossRef]

12. Behrens, B.-A. Finite element analysis of die wear in hot forging processes. CIRP Ann. 2008, 57, 305-308. [CrossRef]

13. Lee, R.; Jou, J. Application of numerical simulation for wear analysis of warm forging die. J. Mater. Process. Technol. 2003, 140, 43-48. [CrossRef]

14. Zhang, C.; Zhao, G.; Li, T.; Guan, Y.; Chen, H.; Li, P. An Investigation of Die Wear Behavior During Aluminum Alloy 7075 Tube Extrusion. J. Tribol. 2013, 135, 011602. [CrossRef]

15. Hsu, Q.-C.; Do, A.T. Formation ability welding seams and mechanical properties of high strength alloy AA7075 when extrusion hollow square tube. Int. J. Precis. Eng. Manuf. 2015, 16, 557-566. [CrossRef]

16. Huang, H.; Chen, X.; Fan, B.; Jin, Y.; Shu, X. Initial billet temperature influence and location investigation on tool wear in cross wedge rolling. Int. J. Adv. Manuf. Technol. 2015, 79, 1545-1556. [CrossRef]

17. Hariprasad, T.; Shivalingappa, D.; Nagaraj, A.; Manivasagam, G. The use of artificial neural network for the prediction of wear loss of aluminium-magnesium alloys. Int. J. Comput. Aided Eng. Technol. 2015, 7, 72. [CrossRef]

18. Huang, C.; Jia, X.; Zhang, Z. A Modified Back Propagation Artificial Neural Network Model Based on Genetic Algorithm to Predict the Flow Behavior of 5754 Aluminum Alloy. Materials 2018, 11, 855. [CrossRef]

19. Syarif, J.; Detak, Y.P.; Ramli, R. Modeling of Correlation between Heat Treatment and Mechanical Properties of Ti-6Al-4V Alloy Using Feed Forward Back Propagation Neural Network. ISIJ Int. 2010, 50, 1689-1694. [CrossRef]

20. Li, X.; Lu, H.; Wang, P. Parameters Optimization of $\gamma$-Ti-46.6Al-1.4Mn-2Mo Alloy by Hot-Pressing Sintering and its Microstructures. Key Eng. Mater. 2013, 551, 92-99. [CrossRef]

21. Jiang, X.; Li, S. BAS: Beetle Antennae Search Algorithm for Optimization Problems. Int. J. Robot. Control. 2018, 1, 1. [CrossRef]

22. Jiang, X.; Li, S. Beetle antennae search without parameter tuning (BAS-WPT) for multi-objective optimization. Filomat 2020, 34, 5113-5119. [CrossRef]

23. Archard, J.F. Contact and Rubbing of Flat Surfaces. J. Appl. Phys. 1953, 24, 981-988. [CrossRef]

24. Snape, R.; Clift, S.; Bramley, A. Sensitivity of finite element analysis of forging to input parameters. J. Mater. Process. Technol. 1998, 82, 21-26. [CrossRef]

25. Colás, R.; Ramírez, J.; Sandoval, I.; Morales, J.C.; Leduc, A.L. Damage in hot rolling work rolls. Wear 1999, 230, 56-60. [CrossRef]

26. Xia, Y.; Shu, X.; Zhu, D.; Pater, Z.; Bartnicki, J. Effect of process parameters on microscopic uniformity of cross wedge rolling of GH4169 alloy shaft. J. Manuf. Process. 2021, 66, 145-152. [CrossRef]

27. Sekine, Y.; Soyama, H. Evaluation of the surface of alloy tool steel treated by cavitation shotless peening using an eddy current method. Surf. Coat. Technol. 2009, 203, 2254-2259. [CrossRef]

28. Kim, K.; Yang, H. Densification behavior of titanium alloy powder during hot pressing. Mater. Sci. Eng. A 2001, 313, 46-52. [CrossRef]

29. Alimirzaloo, V.; Sadeghi, M.H.; Biglari, F.R. Optimization of the forging of aerofoil blade using the finite element method and fuzzy-Pareto based genetic algorithm. J. Mech. Sci. Technol. 2012, 26, 1801-1810. [CrossRef]

30. Hu, H.-J.; Huang, W.-J. Studies on wears of ultrafine-grained ceramic tool and common ceramic tool during hard turning using Archard wear model. Int. J. Adv. Manuf. Technol. 2013, 69, 31-39. [CrossRef]

31. Ji, H.; Peng, Z.; Pei, W.; Xin, L.; Ma, Z.; Lu, Y. Constitutive equation and hot processing map of TA15 titanium alloy. Mater. Res. Express 2020, 7, 046508. [CrossRef] 
32. Landgrebe, D.; Steger, J.; Böhmichen, U.; Bergmann, M. Modified Cross-Wedge Rolling for Creating Hollow Shafts. Procedia Manuf. 2018, 21, 53-59. [CrossRef]

33. Jin, J.; Wang, X.; Deng, L.; Luo, J. A single-step hot stamping-forging process for aluminum alloy shell parts with nonuniform thickness. J. Mater. Process. Technol. 2016, 228, 170-178. [CrossRef]

34. Ghani, J.; Choudhury, I.; Hassan, H. Application of Taguchi method in the optimization of end milling parameters. J. Mater. Process. Technol. 2004, 145, 84-92. [CrossRef]

35. Sivapragash, M.; Kumaradhas, P.; Retnam, S.J.; Joseph, X.F.; Pillai, U. Taguchi based genetic approach for optimizing the PVD process parameter for coating ZrN on AZ91D magnesium alloy. Mater. Des. 2016, 90, 713-722. [CrossRef]

36. Peng, W.-F.; Yan, C.; Zhang, X.; Shu, X.-D.; Huang, G.-X.; Xu, D.-M. Influence of process parameters on interfacial tensile strength of cross-wedge rolling of 42CrMo/Q235 laminated shafts. J. Iron Steel Res. Int. 2018, 25, 1003-1009. [CrossRef]

37. Bulzak, T.; Pater, Z.; Tomczak, J.; Majerski, K. Hot and warm cross-wedge rolling of ball pins-Comparative analysis. J. Manuf. Process. 2019, 50, 90-101. [CrossRef]

38. Peng, Z.; Ji, H.; Pei, W.; Liu, B.; Song, G. Constitutive relationship of TC4 titanium alloy based on back propagating (BP) neural network (NN). Metalurgija 2021, 60, 277-280.

39. Song, C.D.; Kong, J.; Che, L. Prediction of TC16 Alloy Deformation Behavior Based on BP Neural Network. Adv. Mater. Res. 2013, 850-851, 96-101. [CrossRef]

40. Guo, L.-F.; Li, B.-C.; Zhang, Z.-M. Constitutive relationship model of TC21 alloy based on artificial neural network. Trans. Nonferrous Met. Soc. China 2013, 23, 1761-1765. [CrossRef]

41. Mandal, S.; Sivaprasad, P.; Venugopal, S.; Murthy, K.; Raj, B. Artificial neural network modeling of composition-process-property correlations in austenitic stainless steels. Mater. Sci. Eng. A 2008, 485, 571-580. [CrossRef]

42. Schölkopf, B.; Platt, J.; Shawe-Taylor, J.; Smola, A.J.; Williamson, R.C. Estimating the Support of a High-Dimensional Distribution. Neural Comput. 2001, 13, 1443-1471. [CrossRef] [PubMed] 